\title{
Biosurfactants and Bioemulsifiers Biomedical and Related Applications - Present Status and Future Potentials
}

\author{
Letizia Fracchia ${ }^{1}$, Massimo Cavallo ${ }^{1}$, \\ Maria Giovanna Martinotti ${ }^{1}$ and Ibrahim M. Banat ${ }^{2}$ \\ ${ }^{1}$ Department of Chemical, Food, Pharmaceutical and Pharmacological Sciences, \\ Drug and Food Biotechnology Center, \\ Università del Piemonte Orientale "Amedeo Avogadro", Novara, \\ ${ }^{2}$ School of Biomedical Sciences, Faculty of Life and Health Sciences, \\ University of Ulster, Coleraine, N. Ireland, \\ ${ }^{1}$ Italy \\ 2UK
}

\section{Introduction}

Many microorganisms are able to produce a wide range of amphipathic compounds, with both hydrophilic and hydrophobic moieties present within the same molecule which allow them to exhibit surface activities at interfaces and are generally called biosurfactants or bioemulsifiers. These surface-active compounds (SAC) are mainly classified according to their mode of action, molecular weight and general physico-chemical properties.

In literature, the terms 'biosurfactants' and 'bioemulsifiers' are often used interchangeably, however in general those that reduce surface and interfacial tension at gas-liquid-solid interfaces are called biosurfactants and those that mainly reduce the interfacial tension between immiscible liquids or at the solid-liquid interfaces leading to the formation of more stable emulsions are called bioemulsifiers or bioemulsans. The former group includes lowmolecular-weight compounds, such as lipopeptides, glycolipids, proteins, while the latter includes high-molecular-weight polymers of polysaccharides, lipopolysaccharides proteins or lipoproteins (Smyth et al., 2010a, 2010c).

In heterogeneous systems, biosurfactants tend to aggregate at the phase boundaries or interfaces. They form a molecular interfacial film that affects the properties (surface energy and wettability) of the original surface. This molecular layer, in addition to lowering the surface tension in liquids, also lowers the interfacial tension between different liquid phases on the interfacial boundary existing between immiscible phases and therefore can have an impact on the interfacial rheological behaviour and mass transfer.

When at interfaces (solid- liquid, liquid-liquid or vapour-liquid), the hydrophobic moiety of the surface active molecules aggregates at the surface facing the hydrophobic phase (usually the oil phase) while the hydrophilic moiety is oriented towards the solution or hydrophilic phase (mainly water). Their diverse functional properties namely, emulsification, wetting, 
foaming, cleansing, phase separation, surface activity and reduction in viscosity of heavy liquids such as crude oil, make them suitable for utilization for many industrial and domestic application purposes (Gautam \& Tiagi, 2006; Franzetti et al., 2010a; Perfumo et al., 2010a; Satpute et al., 2010b).

During the past two decades biosurfactants have been under continuous investigation as a potential replacement for synthetic surfactants and are expected to have several industrial and environmental applications mainly related to detergency, emulsification, dispersion and solubilisation of hydrophobic compounds (Banat et al., 2000). In addition, biosurfactants present several advantages over surfactants of a chemical origin, particularly in relation to their biodegradability, environmental compatibility, low toxicity, high selectivity and specific activity at extreme temperatures, $\mathrm{pH}$ and salinity (Banat 1995a, 1995b). Due to all these properties, they have steadily gained increased significance in industrial and environmental applications such as bioremediation, soil washing, enhanced oil recovery and other general oil processing and related industries (Perfumo et al., 2010b). Furthermore, potential commercial applications in several other industries including paint, cosmetics, textile, detergent, agrochemical, food and pharmaceutical industries begin to emerge (Banat et al., 2000).

Numerous investigations in the field of biosurfactants/bioemulsifiers are leading to the discovery and description of many interesting chemical and biological properties and potential biomedical therapeutic and prophylactic applications. In this chapter we will focus on the most recent and appealing biomedical and therapeutic applications of biosurfactants and bioemulsifiers with special emphasis on the most recent results in the fields of biotechnology, nanotechnology and bioengineering.

\section{Classification, properties and functional mechanisms of microbial surface- active compounds}

Microbial surface-active compounds are a range of structurally diverse molecules produced by different microorganisms and are mostly therefore classified by their structural features, the producing organism and their molecular mass. Their hydrophilic moiety is mainly comprised of an acid, peptide cations, or anions, mono-, di- or polysaccharides while their hydrophobic moiety can be an unsaturated or saturated hydrocarbon chains or fatty acids. The structural orientation on the surfaces and inter phases confers the range of properties, such as the ability to lower surface and interfacial tension of liquids and the formation of micelles and microemulsions between these different phases (Chen et al., 2010a, 2010b).

\subsection{Low molecular weight compounds}

\subsubsection{Lipopeptides}

Microbial surface-active compounds can be roughly divided into low molecular weight molecules that efficiently reduce surface and interfacial tension (biosurfactants) (Fig. 1.), and high molecular weight polymers that stabilize emulsions but do not lower the surface tension as much (bioemulsans or bioemulsifiers) (Fig. 2.) (Neu, 1996; Rosenberg, 2006; Rosenberg \& Ron, 1997; Smyth et al., 2010a, 2010c).

The most studied low-molecular-weight biosurfactant compounds are lipopeptides and glycolipids. Lipopeptides are mainly produced by members of the Bacillus species; they are composed of different families and each family is constituted of several variants, which can differ in their fatty acid chain and their peptide moiety (Dastgheib et al., 2008; Jacques, 2010; Thavasi et al., 2008, 2011). 
<smiles>CC(C)CCCCCCCCCC(CC(=O)NC(CCC(=O)O)C(=O)NC(CC(C)C)C(=O)NC(CC(C)C)C(=O)NC(C(=O)NC(CC(=O)O)C(=O)NC(CC(C)C)C(=O)NC(CC(C)C)C(=O)NC(CC(C)C)C(=O)O)C(C)C)NC(=O)C(C)C</smiles>

Surfactin

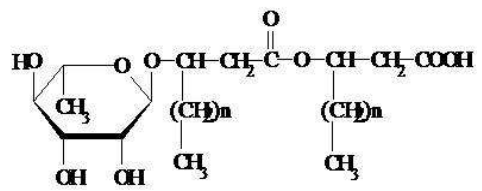

Monorhamnolipid

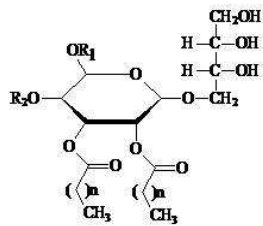

Mannosylerythritol lipid

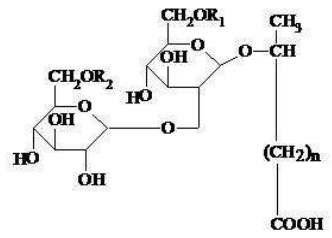

Acidic Sophorolipid

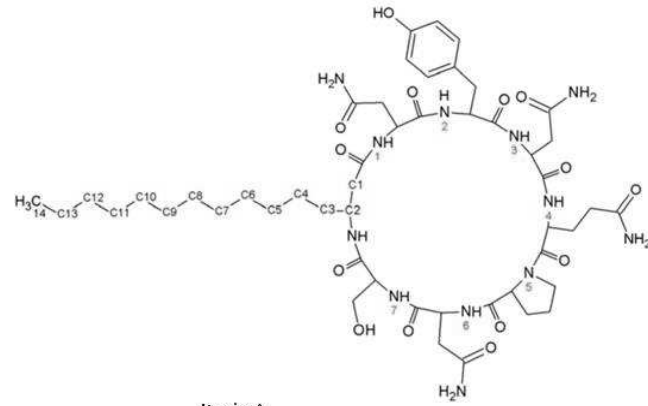

Iturin $A$
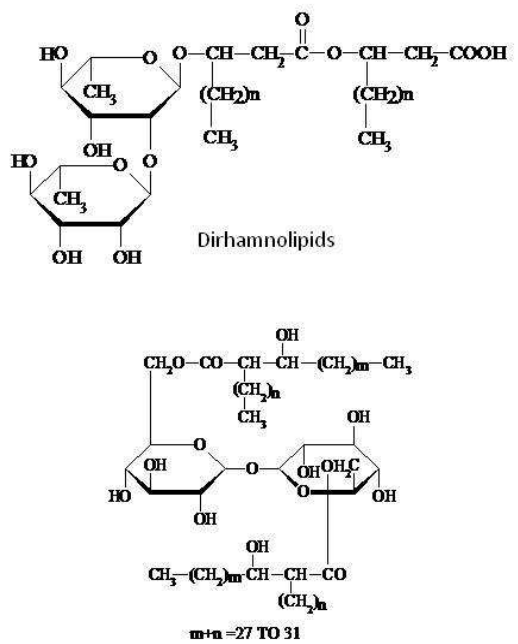

Trehalose dimycolate

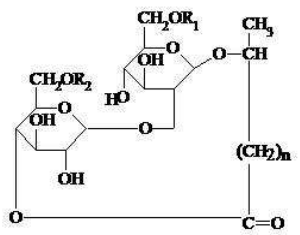

Lactonic Sophorolipid

Fig. 1. Chemical structures of the main low molecular weight microbial surface active compounds reported; surfactin, iturin A, mono \& di-rhamnolipids, mannosylerythritol lipids, dimycolates trehalose lipids, acidic and lactonic sophorolipids.

Surfactin, a cyclic lipopeptide produced by Bacillus subtilis is considered the most active biosurfactant discovered so far (Ron \& Rosenberg, 2001). Surfactin was discovered by 
Arima et al., (1968) from the culture broth of Bacillus subtilis and it was named thus due to its exceptional surfactant activity (Peypoux et al., 1999). Natural surfactins are a mixture of isoforms A, B, C and D which are classified according to the differences in their amino acid sequences and possess various physiological properties (Shaligram \& Singhal, 2010). Surfactin is composed of a seven amino-acid ring structure coupled to a fatty-acid chain via a lactone linkage. Surfactin-A has L-leucine, surfactin-B has L-valine and surfactin-C has L-isoleucine at the amino acid position involved in the lactone ring formation with the C14-C15 $\beta$-hydroxy fatty acid. The amino-acid residues may vary and the presence of these variants can be related to alterations in the culture conditions such as providing substrate containing some specific amino-acid residues in the culture media (Jacques, 2010).

Another surfactin related compound is lichenysin, a lipopeptide discovered in the supernatant of Bacillus licheniformis culture (Horowitz et al., 1990). Its chemical structure and physio-chemical properties are similar to surfactin (McInerney et al., 1990). In particular, lichenysin has Glutamine amino-acid in position 1 while surfactin has Glutamic acid. Other surfactin-like compounds are pumilacidin A, B, C, D, E, F and G, a complex of acylpeptide antibiotics isolated from Bacillus pumilus culture supernatants with interesting antiviral properties (Morikawa et al., 1992; Naruse et al., 1990). Among the lipopeptides belonging to the iturin family, iturin $\mathrm{A}$ is the most studied compound. It is a heptapeptide interlinked with a $\beta$-amino-acid fatty acid with carbon chain length from C14 to C17 (Peypoux, 1978, as cited in Jacques, 2010) produced by Bacillus subtilis strains reported to have antifungal activities (Besson et al., 1976).

Other members of the iturin family are iturin $\mathrm{C}$, bacillomycin D, F, and Lc and mycosubtilin (Bonmatin et al., 2003). The family of fengycins includes fengycins A and B, lipodecapeptides which differ by their amino-acid residue in position 6 that can be Alanine or Valine and are known for their interesting fungitoxic and immunomodulating activities (Jacques, 2010). Other interesting lipopeptides are serrawettins, nonionic cyclodepsipeptide biosurfactants produced by Serratia marcescens (Matsuyama et al., 2010) and implicated with anti-tumor and anti-nematode activities.

\subsubsection{Glycolipids}

Are commonly mono or disaccharides compounds acylated with long chain fatty acids or hydroxyl fatty acids. Among them, rhamnolipids, mannosylerythritol lipids (MELs), sophorolipids and trehalolipids are the best-studied structural subclasses.

Rhamnolipids are glycosides, produced mainly by Pseudomonas aeruginosa and by the Burkholderia genus, that are composed of one (for mono-rhamnolipids) or two (for dirhamnolipids) rhamnose sugar moieties linked to one or two $\beta$-hydroxyfatty acid chains (Perfumo et al., 2006; Raza, 2009). These molecules display high surface activities and many potential applications in the biomedical field due to their antibacterial, antifungal, antiviral, antiadhesive reported properties (Abalos et al., 2001; Cosson et al., 2002; Kim et al., 2000; Remichkova et al., 2008; Sotirova et al., 2008; Yoo et al., 2005). They have also been used in the preparation of nanoparticles (Palanisamy \& Raichur, 2009; Xie et al., 2006) and microemulsions (Nguyen \& Sabatini, 2009; Xie et al., 2007).

The mannosylerythritol (MELs) glycolipids are produced by the yeasts strains of the genus Pseudozyma sp. and Ustilago sp. from soybean oil or $n$-alkane (Arutchelvi \& Doble, 2010). MELs are a mixture of partially acylated derivative of 4-O- $\beta$-D-mannopyranosyl-D-erythritol, 
containing $\mathrm{C}_{2: 0}, \mathrm{C}_{12: 0}, \mathrm{C}_{14: 0}, \mathrm{C}_{14: 1}, \mathrm{C}_{16: 0}, \mathrm{C}_{16: 1}, \mathrm{C}_{18: 0}$ and $\mathrm{C}_{18: 1}$ fatty acids as the hydrophobic groups (Bhattacharjee et al., 1970, as cited in Arutchelvi \& Doble, 2010). Based on the degree of acetylation at $\mathrm{C} 4$ and $\mathrm{C} 6$ position, and their order of appearance on the thin layer chromatography, the MELs are classified into MEL-A, -B, -C and -D (Arutchelvi \& Doble, 2010). MEL-A representing the diacetylated compound while MEL-B and MEL-C are monoacetylated at C6 and C4, respectively. The completely de-acetylated structure is known as MEL-D (Rau et al., 2005, as cited in Arutchelvi \& Doble, 2010).

MELs have recently gained attention due to their environmental compatibility, mild production conditions, structural diversity, self-assembling properties and versatile biochemical functions. In particular, interesting applications have been described in the biomedical field as antimicrobial, antitumor and immunomodulating molecules, in the biotechnological field for gene and drug delivery, and in cosmetic applications as skin moisturizers (Arutchelvi \& Doble, 2010).

Sophorolipids are another extracellular glycolipids synthesized by some yeast species including Candida bombicola, Candida apicola, Rhodotorula bogoriensis, Wickerhaminella domercqiae and Candida batistae (Van Bogaert \& Soetaert, 2010). They consist of two glucose units linked $\beta-1,2$. The $6-$ and 6 -hydroxyl groups are generally acetylated. The lipid portion is connected to the reducing end through a glycosidic linkage. The terminal carboxyl group of the fatty acid can be in the lactonic form or hydrolyzed to generate an anionic surfactant (Rosenberg \& Ron, 1999). Sophorolipids have been reported suitable for a number of application in the biomedical field including use as antimicrobial, antiviral and anticancer. They also have been used in the synthesis of metal-bound nanoparticles in cosmetic and pharmacodermatological products (Van Bogaert \& Soetaert, 2010).

Trehalose lipids are also a glycolipids containing threhalose as the sugar moiety which is a non-reducing disaccharide in which the two glucose units are linked in an a,a-1,1-glycosidic linkage. It is the basic component of the cell wall glycolipids in Mycobacteria and Corynebacteria (Franzetti et al., 2010b). The most reported trehalose lipid is trehalose 6,6'dimycolate, which is a a-branched chain mycolic acid esterified to the C6 position of each glucose. Different trehalose containing glycolipids are known to be produced by several other microorganisms belonging to mycolates group, such as Arthrobacter, Nocardia, Rhodococcus and Gordonia. Rhodococcus genus in particular produced several types of trehalose lipids as reported by Lang \& Philp (1998). These glycolipids vary in the number and overall chain length (C20-C90) of the esterified fatty acids. Beside their known industrial applications, trehalose lipids recently attracted attention to their functions in cell membrane interaction and their potential as antitumor therapeutic agents (Aranda et al., 2007, Harland et al., 2009, Imasato et al., 1990, Isoda et al., 1995, as cited in Shao, 2010; Ortiz et al., 2008, 2009; Zaragoza et al., 2009, 2010).

\subsection{High molecular weight biosurfactants}

These are generally grouped together as polymeric biosurfactants. They are produced by a number of different bacteria and are composed of lipoproteins, proteins, polysaccharides, lipopolysaccharides or complexes containing several of these structural types (Ron \& Rosenberg, 2001; Rosenberg \& Ron, 1997, 1999). The most commonly studied biopolymer is emulsan (Fig. 2.), a lipopolysaccharide isolated from Acinetobacter calcoacetius RAG-1 ATCC 31012 with a molecular weight of around 1,000 kDa (Rosenberg et al., 1979). 


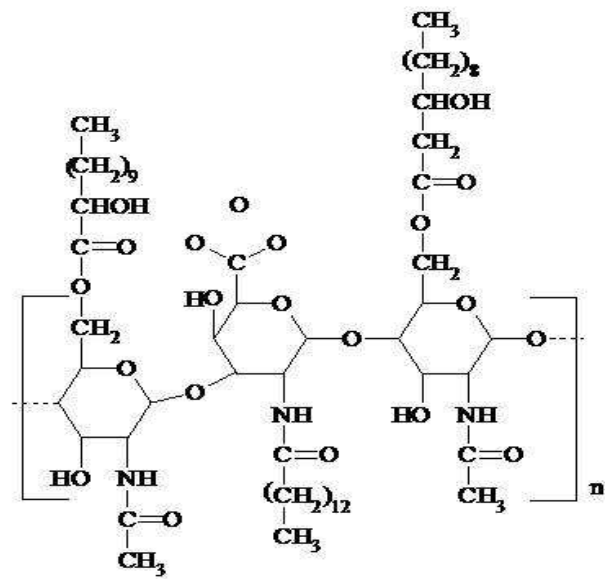

Emulsan

Fig. 2. Chemical structure of most known high molecular weight microbial surface active compound; emulsan.

RAG-1 emulsan is a complex of an anionic heteropolysaccharide and protein (Rosenberg \& Kaplan, 1987, as cited in Rosenberg \& Ron, 1999). Its surface activity is due to the presence of fatty acids, comprising $15 \%$ of the emulsan dry weight, which are attached to the polysaccharide backbone via O-ester and N-acyl linkages (Belsky et al., 1979, as cited in Rosenberg \& Ron, 1999).

Another high molecular weight biosurfactant is alasan, a complex of an anionic polysaccharide and a protein with a molecular weight of around 1,000 $\mathrm{kDa}$ isolated from Acinetobacter radioresistens (Navon-Venezia et al., 1995, as cited in Smyth et al., 2010c). These high molecular weight biosurfactants generally possess effective emulsifying activity and are called bioemulsifiers. A large number of other polymeric compounds have been discovered but remain partially or totally uncharacterized (Smyth et al., 2010c). Little is known in general about these bioemulsifiers other than the producing organism and the overall chemical composition of the crude mixture. Halomonas eurihalina produces an extracellular sulfated heteropolysaccharide (Calvo et al., 1998, as cited in Rosenberg \& Ron, 1999). Pseudomonas tralucida produced an extracellular acetylated polysaccharide that was effective in emulsifying several insecticides (Appaiah \& Karanth 1991, as cited in Rosenberg \& Ron, 1999).

Several bioemulsifiers are effective at high temperature, including the protein complex from Methanobacterium thermoautotrophium (De Acevedo et al., 1996, as cited in Rosenberg \& Ron, 1999) and the protein-polysaccharide-lipid complex of Bacillus stearothermophilus ATCC 12980 (Gunjar et al., 1995, as cited in Rosenberg \& Ron, 1999). Yeasts produce a number of emulsifiers, which are particularly interesting because of the food-grade status of several yeasts which allows use in food related industries. Liposan is an extracellular emulsifier produced by Candida lipolytica (Cirigliano \& Carman, 1985, as cited in Rosenberg \& Ron, 1999). It is composed of $83 \%$ carbohydrate and $17 \%$ protein. Mannanprotein emulsifiers are produced by Saccharomyces cerevisiae (Cameron et al., 1988, as cited in Rosenberg \& Ron, 1999). Many of these bioemulsifiers have been used in the food, cosmetic, and petroleum industries (Rosenberg \& Ron, 1999). 


\subsection{Properties and functions of biosurfactants}

There is a growing interest in the study of the physicochemical and biological properties of biosurfactants because of their potential industrial applications (Cameotra \& Makkar, 2004; Desai \& Banat, 1997; Lang, 2002; Rodrigues et al., 2006a; Singh \& Cameotra, 2004). The interesting biological activities displayed by these compounds constitute an added value to their potential uses (Lang et al., 1989; Lang \& Wagner, 1993; Stanghellini \& Miller, 1997, as cited in Sánchez et al., 2010). Due to these reasons, an intense research activity is currently directed toward identification of new biosurfactants and characterization of their chemical and biological properties (Biria et al., 2010; Morita et al., 2009a; Satpute et al., 2010a; Singh \& Cameotra, 2004; Singh et al., 2007).

The most obvious property of biosurfactants compounds is their ability to effectively lower water surface tension, and a number of approaches that measure directly the surface activity of biosurfactants can be used as screening methods for their detection. Among them, the most frequently used as quick and simple techniques are the drop collapse (Bodour and Miller-Maier, 1998) and the oil spreading tests (Morikawa et al., 2000) (Fig. 3).

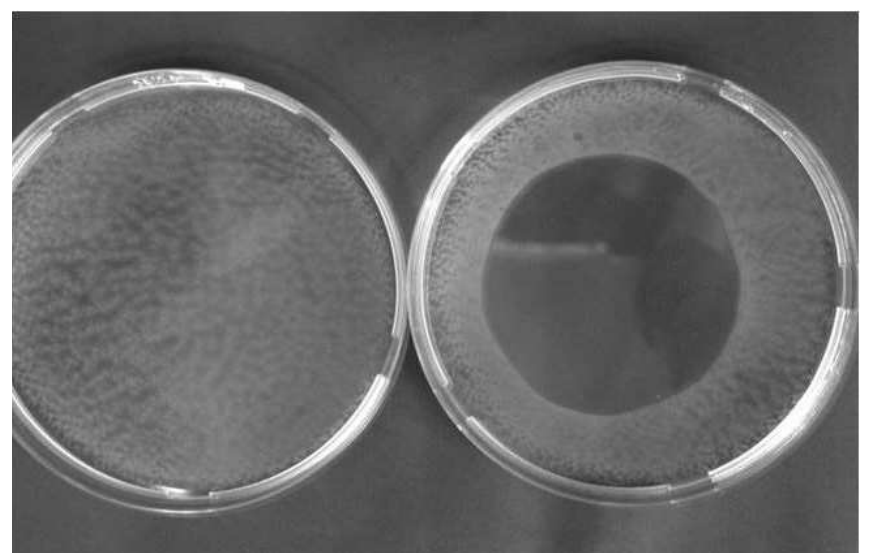

Fig. 3. Oil spreading test. This technique measures the diameter of clear zones caused when a drop of a biosurfactant-containing solution is placed on an oil-water surface (Morikawa et al., 2000). Photo courtesy by Fabrizio Rivardo.

An efficient biosurfactant can reduce the surface tension between pure water and air from $72 \mathrm{mN} / \mathrm{m}$ to less than $30 \mathrm{mN} / \mathrm{m}$. Surfactin, as one of the most powerful biosurfactants, can reduce the surface tension of water from $72 \mathrm{mN} / \mathrm{m}$ to $27 \mathrm{mN} / \mathrm{m}$ (which is close to the minimum detectable value) at a concentration as low as $10 \mu \mathrm{M}$ (Seydlová \& Svobodová, 2008). Rhamnolipids can similarly achieve such level of reduction (Hisatsuka et al., 1971, as cited in Muthusamy et al., 2008; Mohammad Abdel-Mawgoud et al., 2010). The sophorolipids from $T$. bombicola have been reported to reduce the surface tension to $33 \mathrm{mN} / \mathrm{m}$ (Muthusamy et al., 2008) while MELs and trehalose lipids to less than $30 \mathrm{mN} / \mathrm{m}$ (Arutchelvi \& Doble, 2010; Shao et al., 2010).

As surfactant monomers are added into solution, the surface or interfacial tension will decrease until the biosurfactant reaches the critical micelle concentration (CMC). The CMC is defined as the minimum concentration necessary to initiate micelle formation (Becher, 1965). Above the CMC no further reduction in surface or interfacial tension is observed. At 
the $\mathrm{CMC}$, surfactant monomers begin to spontaneously associate into structured aggregates such as micelles, vesicles or continuous bilayers. These aggregates are produced as a result of numerous weak chemicals interactions such as hydrophobic, van der Waals and hydrogen bonding (Maier, 2003; Raza et al., 2010). Since no chemical bonds are formed, these structures are fluid-like and are easily transformed from one state to another as conditions such as electrolyte concentration and temperature are changed (Lin, 1996).

The aggregate structure depends on the polarity of the solvent in which the surfactant is dissolved. In an aqueous solution, the polar head groups of a micelle will be oriented outward toward the aqueous phase, and the hydrophobic tails will associate in the core of the micelle within an oil-in-water micelle. In contrast, in oil, the polar head groups will associate in the center of the micelle while the hydrophobic tails will be oriented toward the outside within the water-in-oil micelle (Soberón-Chávez \& Maier, 2010). Efficient surfactants have a low CMC, i.e. less surfactant is necessary to decrease the surface tension (Seydlová \& Svobodová, 2008).

Biosurfactants are most effective and efficient at their CMC which can be 10-40 times lower than that of chemical surfactants, i.e. less surfactant is necessary to get a maximum decrease in surface tension (Desai \& Banat, 1997). Another important property for industrial and biotechnological applications is that most biosurfactants surface activities are not affected by environmental conditions such as temperature and $\mathrm{pH}$ (Muthusamy et al., 2008) particularly those of glycolipids composition. It has been reported that lichenysin from $B$. licheniformis JF2 was not affected by temperature (up to $50{ }^{\circ} \mathrm{C}$ ), $\mathrm{pH}(4.5-9.0)$ and $\mathrm{NaCl}$ and $\mathrm{Ca}$ concentrations up to 50 and $25 \mathrm{~g} / 1$ respectively. A lipopeptide from $B$. subtilis LB5a was also stable after autoclaving $\left(121^{\circ} \mathrm{C} / 20 \mathrm{~min}\right)$ and after 6 months at $-18^{\circ} \mathrm{C}$; the surface activity did not change from $\mathrm{pH} 5$ to 11 and $\mathrm{NaCl}$ concentrations up to $20 \%$ (Muthusamy et al., 2008).

Moreover, unlike synthetic surfactants, microbial-produced compounds are easily degraded and are generally considered as low or non-toxic products and therefore, appropriate for pharmaceutical, cosmetic and food uses. Although little is known about the toxicity of microbial surfactants, some data in the literature suggest that they are less toxic than synthetic surfactants (Muthusamy et al., 2008). The synthetic anionic surfactant (Corexit) for example had an LC50 (lethal concentration to $50 \%$ of test species) against Photobacterium phosphoreum at approximately ten times lower concentrations than that for rhamnolipids, demonstrating the higher toxicity of the chemical-derived surfactant. It was also reported that biosurfactants needed higher effective concentration to decrease $50 \%$ of test population values (EC50) and were degraded faster than commercial dispersants. In another report, biosurfactants from $P$. aeruginosa were noted to have much less toxic and mutagenic activities when compared to synthetic surfactant Marlon A-350, which is widely used in the industry.

Understanding the functional mechanisms of biosurfactants and bioemulsifiers is of great help to discover interesting applications. Surfactin, one of the most powerful biosurfactants, is known to destabilize membranes disturbing their integrity and permeability (Bernheimer et al., 1970). This is due to changes in physical membrane structure or through disrupting protein conformations which alter important membrane functions such as transport and energy generation (Ortiz et al., 2008, 2009; Sánchez et al., 2009, 2010; Sotirova et al., 2008; Van Hamme et al., 2006; Zaragoza et al., 2009).

The molecular mechanisms of surfactin interactions with membrane structures have been described by Shaligram \& Singhal (2010) and by Seydlová \& Svobodová (2008). A key step for membrane destabilization and leakage is the dimerization of surfactin into the bilayer (Carrillo et al., 2003). The hypothetical mechanisms of surfactin interactions with 
membranes exhibit a complex pattern of effects such as insertion into the lipid bilayers, chelating mono- and divalent cations, modification of membrane permeability by channel formation or membrane solubilization by a detergent-like mechanism. In vitro, the incorporation of surfactin into the membrane gives rise to dehydration of the phospholipid polar head groups and the perturbation of lipid packing which strongly compromise the bilayer stability, leading to the disturbance of the membrane barrier properties.

These structural fluctuations may well explain the primary mode of the antibiotic action and the other important biological effects of this lipopeptide (Carrillo et al., 2003). The extent of perturbation of the phospholipid bilayer correlates with the concentration of surfactin. At low concentrations surfactin penetrates readily into the cell membrane, where it is completely miscible with the phospholipids and forms mixed micelles. At moderate concentrations, the lipopeptide forms domains segregated within the phospholipid bilayer that may contribute to the formation of ion-conducting pores in the membrane leading to membraine disruption and permeabilization at high concentrations, showing a stronger activity than that of Triton (Heerklotz et al., 2007, as cited in Seydlová \& Svobodová, 2008).

As biological amphiphilic molecules, biosurfactants naturally tend to self-assemble into hierarchically ordered structures using hydrogen bonding, hydrophobic and van der Waals interactions (Kitamoto et al., 2009). Glycolipids, and in particular MELs, are well known for their self-assembling properties, that are influenced by the stereochemistry of the saccharide head groups (Kitamoto et al., 2005). Some of glycolipid type surfactants, which possess relatively large hydrophilic head groups as compared to the hydrophobic parts, generally form micelles in a dilute aqueous solution. Other than spherical micelles, they also form oblate (disk-like) and prolate (rod-like) structures (Söderman, 2000, as cited in Kitamoto et al., 2009). As the surfactant concentration further increases, glycolipid/water systems start to form a range of liquid crystalline phases. In particular, glycolipid biosurfactants spontaneously self-assemble into a variety of molecular assemblies with well-defined and/or unique structures, such as sponge (L3), cubic (V2), hexagonal (H2), or lamellar $\left(\mathrm{L}_{\mathrm{\alpha}}\right)$ configurations (Imura et al., 2007, as cited in Kitamoto et al., 2009).

Among these molecular assemblies, vesicles are one of the most intensively studied ones. MELs in particular, due to their efficient molecular orientation property and effective balance between hydrophilic and hydrophobic groups, are able to form giant vesicles of diameter larger than $10 \mu \mathrm{m}$ (Kitamoto et al., 2002). In comparison, rhamnolipids show a pHsensitive conversion of molecular assemblies due to the presence of a carboxyl group on the side chain (Kitamoto et al., 2002). This leads rhamnolipids to form micelles at $\mathrm{pH}$ more than 6.8, lipid particles at $\mathrm{pH}$ 6.6-6.2, lamella structures at $\mathrm{pH}$ 6.5-6.0, and finally vesicles in the size of 50-100 $\mathrm{nm}$ at $\mathrm{pH}$ 5.8-4.3. Glycolipid biosurfactant-based vesicles or bilayer membranes appear, thus, to be very promising for exploiting useful nanostructured materials and/or systems.

Another function of microbial surface-active molecules with interesting biotechnological potential is the ability to form stable emulsions (Fig. 4.). High molecular-mass biosurfactants are in general better emulsifiers than low-molecular-mass biosurfactants and are thus called bioemulsifiers. Bioemulsifiers, can form and stabilize oil in water or water in oil emulsions, but are not necessarily efficient detergents that are able to demonstrate remarkable surface tension reduction (Dastgheib et al., 2008). Emulsions can be produced with prolonged lifespan of months and years. Liposan, for example, does not reduce surface tension, but has been used successfully to emulsify edible oils (Cirigliano \& Carman, 1985). Emulsan is an effective emulsifier at low concentrations (0.01-0.001\%) representing emulsan-to- 
hydrocarbon ratios of 1:100 to 1:1000, while exhibiting considerable substrate specificity (Ron \& Rosemberg, 2001). Polymeric surfactants offer additional advantages because they coat droplets of oil, thereby forming stable emulsions. This property is especially useful for making oil/water emulsions for cosmetics and food industries (Muthusamy et al., 2008).

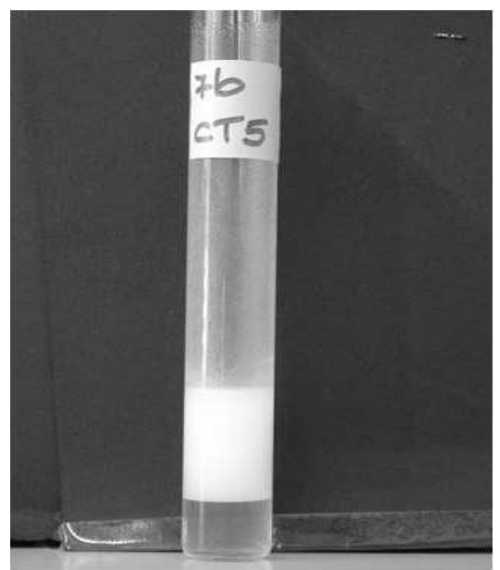

Fig. 4. Example of emulsion produced by the bioemulsifier extracted from the bacterial strain 7bCT5, isolated from a Cambodian soil. This emulsion is stable since 2009.

\subsubsection{Natural roles}

Although biosurfactants are produced by a large number of microorganisms and are clearly significant in many aspects of growth, it is difficult to generalize on their roles in microbial physiology. Due to their very diverse chemical structures and surface properties, different groups of biosurfactants may have different natural roles in the growth of the producing microorganisms and probably provide advantages in a particular ecological niche. Ron \& Rosenberg, (2001) and Van Hamme et al., (2006) recently reviewed the physiological roles of microbial surface-active compounds. Some biosurfactants are essential for the motility of the microorganisms (gliding and swarming). For example, serrawettin plays a fundamental role for surface locomotion and access to water repelling surfaces for Serratia marcescens whereas surfactin, together with flagellar biosynthesis, are crucial for swarming motility in B. subtilis (Arutchelvi et al., 2008; Van Hamme et al., 2006). Bioemulsifiers also play an important role in regulating the attachment-detachment of microorganisms to and from surfaces (Van Hamme et al., 2006).

In addition, bioemulsifiers are involved in cell-to-cell interactions such as bacterial pathogenesis, quorum sensing and biofilm formation, maintenance and maturation. Rhamnolipids, for example, are essential to maintain the architecture of the biofilms and are considered as one of the virulence factors in Pseudomonas sp. (Arutchelvi et al., 2008; Ron \& Rosenberg, 2001; Van Hamme et al., 2006). Rhamnolipids, mannosylerythritol lipid and surfactin show antimicrobial and antibiotic properties thus conferring a competitive advantage to the organism during colonization and cell-cell competition. In addition cellular differentiation, substrate accession and resistance to toxic compounds are all roles attributed to microbial surface-active compounds. Their most widespread role however is believed to be the interaction between microbes and insoluble substrates such as 
hydrocarbons. Some biosurfactants/bioemulsifiers enhance the growth of bacteria on hydrophobic water-insoluble substrates by increasing their bioavailability, presumably by increasing their surface area, desorbing them from surfaces and increasing their apparent solubility (Neu, 1996; Ron \& Rosenberg, 2001; Van Hamme et al., 2006).

\section{Biomedical applications of microbial surface-active compounds}

The use and potential commercial applications of biosurfactants in the medical field have increased during the past decade. Their antibacterial, antifungal and antiviral activities make them relevant molecules for applications in combating many diseases and as therapeutic agents. Furthermore, biosurfactants are generally considered safer than synthetic pharmaceuticals, due to their biological origin. Their pertinence in these fields is related to their biological properties such as the ability to disrupt membranes leading to cell lysis and metabolite leakage through increased membrane permeability and hence antimicrobial activity. Moreover, similarly to organic-conditioning films, their ability to partition at the interfaces can affect the adhesion properties of cells/microorganisms. Biomedical applications of biosurfactants have been thoroughly described (Banat et al., 2010; Cameotra \& Makkar, 2004; Rodrigues et al., 2006a; Rodrigues \& Teixeira, 2010; Seydlová \& Svobodová, 2008; Singh \& Cameotra, 2004).

\subsection{Antimicrobial activity of biosurfactants}

The search for new antimicrobial drugs remains a major concern nowadays because of the newly emerged pathogenic microorganisms and traditional others which have become virtually unresponsive to existing antibiotics. In fact, no novel or effective chemical antibiotics have been discovered during the last few decades (Hancock \& Chapelle, 1999). Microbial metabolites have been recognized as a major source of compounds endowed with ingenious structures and potent biological activities (Donadio et al., 2002). Among these, some biosurfactants have been reported to be suitable alternatives to synthetic medicines and antimicrobial agents and may therefore be used as effective and safe therapeutic agents (Banat et al., 2000; Cameotra \& Makkar, 2004; Singh \& Cameotra, 2004).

\subsubsection{Antibacterial activity}

Lipopeptides have the most potent antimicrobial activity and have been a subject of several studies on the discovery of new antibiotics. The antibiotic activity is due to the ability of molecules of lipopeptide biosurfactants to self-associate and form a pore-bearing channel or micellular aggregate inside a lipid membrane (Carrillo et al., 2003; Deleu et al., 2008). Surfactin, in particular, has been associated with several physical and biological actions, such as antimicrobial, antiviral, anti-mycoplasma and haemolytic activities. It can penetrate into the membrane through hydrophobic interactions, thus influencing the ordering of the hydrocarbon chains and thus varying the membrane thickness (Bonmatin et al., 2003). Such membrane disruptions are a nonspecific mode of action and are advantageous for action on different cell membranes of both Gram-positive and Gram-negative bacteria (Lu et al., 2007). It has been suggested that such action by surfactin type peptides on membrane integrity rather than other vital cellular processes may perhaps constitute the next generation of antibiotics (Rodrigues \& Teixeira, 2010). Similar bioactive fractions from the marine Bacillus circulans biosurfactant had antimicrobial action against various Gram-positive and Gramnegative pathogenic and semi-pathogenic bacteria including Micrococcus flavus, Bacillus 
pumilis, Mycobacterium smegmatis, Escherichia coli, Serratia marcescens, Proteus vulgaris, Citrobacter freundii, Proteus mirabilis, Alcaligenes faecalis, Acetobacter calcoaceticus, Bordetella bronchiseptica, Klebsiella aerogenes and Enterobacter cloacae (Das et al., 2008). The chemical identity of this bioactive biosurfactant fraction showed overlapping patterns with that of surfactin lipopeptides and lichenysin. Mild antimicrobial action was also observed against methicillin-resistant Staphylococcus aureus (MRSA) and other MDR pathogenic strains. The biosurfactant was also found to be nonhaemolytic in nature thus indicating possible use as a drug in antimicrobial chemotherapy.

Very recently Huang et al., (2011) evaluated antimicrobial activity of surfactin and polylysine against Salmonella enteritidis in milk using a response surface methodology and showed $S$. enteritidis to be very sensitive to both molecules with minimum inhibitory concentrations of 6.25 and $31.25 \mu \mathrm{g} / \mathrm{mL}$, respectively. The optimization of antimicrobial activity indicated that $S$. enteritidis could be reduced by 6 orders of magnitude at a temperature of $4.45^{\circ} \mathrm{C}$, action time of $6.9 \mathrm{~h}$, and concentration of $10.03 \mu \mathrm{g} / \mathrm{mL}$ (surfactin/polylysine weight ratio, 1:1).

In addition to surfactin, Bacillus subtilis strains produce a broad spectrum of bioactive peptides with great potential for biomedical applications, such as fengycin (Vanittanakom et al., 1986) and the iturin compounds: iturins (Besson et al., 1978; Peypoux et al., 1978), mycosubtilins (Peypoux et al., 1986), and bacillomycins (Peypoux et al., 1984), all of which are amphiphilic surface and membrane-active compounds with potent antimicrobial activities. Huang et al., (2007) reported that a lipopeptide antimicrobial substance produced by $B$. subtilis fmbj strain, which is mainly composed of surfactin and fengycin, was able to inactivate endospores of $B$. cereus through damaging the surface structure of the spores as seen by Transmission Electron Microscopy.

Lichenysin, pumilacidin and polymyxin B (Grangemard et al., 2001; Landman et al., 2008; Naruse et al., 1990; Yakimov et al., 1995) are other antimicrobial lipopeptides produced by Bacillus licheniformis, Bacillus pumilus and Bacillus polymyxa, respectively. Polymyxin B, in particular, due to its high affinity for the lipid moieties of lipopolysaccharide, has shown antibacterial activities against a wide variety of Gram-negative pathogens. Being a cationic agent, it binds to the anionic bacterial outer membrane, leading to a detergent effect that disrupts membrane integrity. Important nosocomial pathogens such as Escherichia coli, Klebsiella spp., Enterobacter spp., Pseudomonas aeruginosa, and Acinetobacter spp. are usually susceptible to polymyxins and considerable activity has been reported against Salmonella spp., Shigella spp., Pasteurella spp., and Haemophilus spp. (Landman et al., 2008).

Another promising example of an antimicrobial lipopeptide that is under commercial development is daptomycin (Cubicin $\left.{ }^{\circledR}\right)$. It has been approved for the treatment of skin infections by the FDA in 2003 (Giuliani et al., 2007, as cited in Seydlová \& Svobodová, 2008). Daptomycin produced by Streptomyces roseosporus has been shown to be highly active against multiresistant bacteria such as MRSA (Tally \& De Bruin, 2000, as cited in Seydlová \& Svobodová, 2008). Another lipopeptide with antimicrobial activity and other interesting biological properties is viscosin, a cyclic lipopeptide from Pseudomonas (Saini et al., 2008).

Glycolipids, both rhamnolipids (Abalos et al., 2001; Benincasa et al., 2004) and sophorolipids (Kim et al., 2002; Van Bogaert et al., 2007) also have shown interesting antimicrobial activities (Fig. 5). Benincasa et al., (2004) reported that a mixture of six rhamnolipides homologues performed very well against Bacillus subtilis with a MIC of $8 \mu \mathrm{g} / \mathrm{mL}$. Mannosylerythritol lipids (MEL-A and MEL-B) produced by Candida antarctica strains have also been reported to exhibit antimicrobial action against Gram-positive bacteria (Kitamoto et al., 1993). 


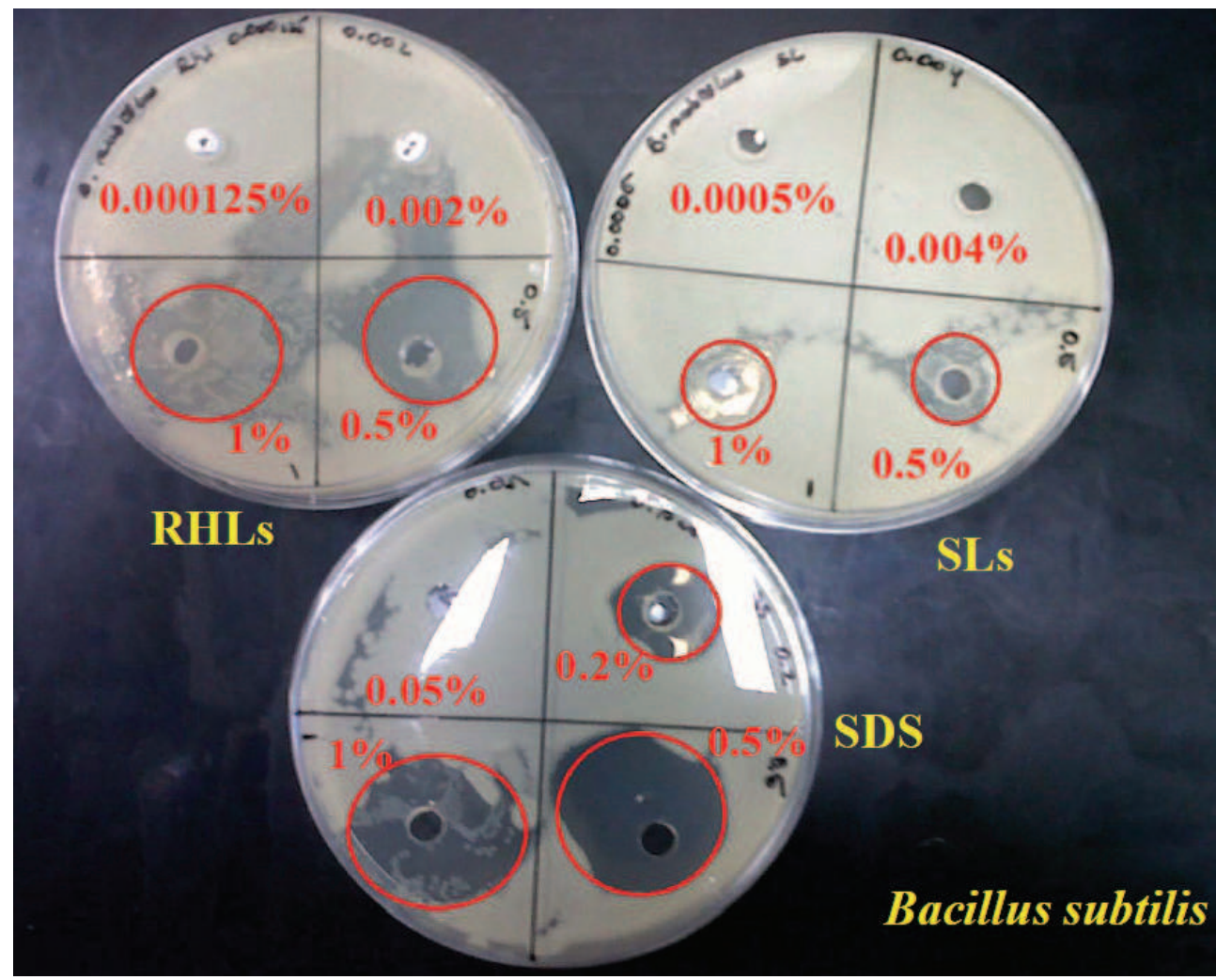

Fig. 5. Measuring antimicrobial activity for rhamnolipids, sophorolipids and SDS at various concentrations above and below the $\mathrm{CMC}$ for these surface active molecules against Bacillus subtilis, red circles showing clearing/inhibition zones.

Very recently, Nitschke et al., (2010) reported rhamnolipids produced by P. aeruginosa LBI with antimicrobial activity against several bacteria and fungi, including Bacillus cereus, Staphylococcus aureus, Micrococcus luteus, Mucor miehei and Neurospora crassa. Another glycolipid, flocculosin, a cellobiose lipid produced by the yeast-like fungus Pseudozyma flocculosa, was particularly effective against Staphylococcus species, including MRSA. Its antibacterial activity was not influenced by the presence of common resistance mechanisms against methicillin and vancomycin and it was able to eliminate $C$. albicans cells in a very short period of time (Mimee et al., 2009).

Trehalose lipids produced by Tsukamurella sp. strain DSM 44370 together with trisaccharide and tetrasaccharide lipids also showed some activity against Gram-positive bacteria, with the exception of the pathogenic strain Staphylococcus aureus, whereas Gram-negatives were either slightly or not inhibited at all (Vollbrecht et al., 1999, as cited in Franzetti et al., 2010b). Studies carried out to elucidate the molecular interactions between this biosurfactant and the lipidic component of the membrane showed that trehalose lipid increased the fluidity of phosphatidylethanolamine and phosphatidylserine membranes and formed domains in the fluid state and did not modify the macroscopic bilayer organization (Ortiz et al., 2008, 2009). 


\subsubsection{Antiviral activity}

Antiviral effects have also been reported for surfactin and its analogues (Naruse et al., 1990). More effective inactivation of enveloped viruses, such as retroviruses and herpes viruses, were noted compared to non-enveloped viruses, suggesting that inhibitory action links may be due to physico-chemical interactions with the virus envelope (Vollenbroich et al., 1997a). Antiviral activity of some lipopeptides therefore may take place as a result of the viral lipid envelope and capsid disintegration due to ion channels formation, with consequent loss of the viral proteins involved in virus adsorption and/or penetration (Jung et al., 2000; Seydlová \& Svobodová, 2008).

In vitro experiments showed that both surfactin and fengycin produced by B. subtilis fmbj were able to inactivate cell-free virus stocks of porcine parvovirus, pseudorabies virus, newcastle disease virus and bursal disease virus and could effectively inhibit infections and replication of these viruses (Huang et al., 2006).

Sophorolipids are also claimed to have activity against human immunodeficiency virus (Shah et al., 2005) and trehalose lipids (namely trehalose dimycolate, TDM) conferred higher resistance to intranasal infection by influenza virus in mice though inducing proliferation of T-lymphocytes bearing gamma/delta T-cell receptors, associated with the maintenance of acquired resistance to the infection (Hoq et al., 1997, as cited in Franzetti et al., 2010b).

Rhamnolipid alginate complex also showed significant antiviral activity against herpes simplex virus types 1 and 2. In particular, they significantly inhibited the herpesvirus cytopathic effect in the Madin-Darby bovine kidney cell line (Remichkova et al., 2008). The suppressive effect of the compounds on herpes simplex virus replication was dosedependent and occurred at concentrations lower than the critical micelle concentration.

\subsubsection{Anti mycoplasma activity}

Some investigations have shown interesting anti-mycoplasma effects for surfactins. Mycoplasma contamination in cell culture is a frequently occurring serious limitation to biomedical research, particularly when it affects the irreplaceable cell lines which ultimately ends up destroyed. Earlier studies showed that surfactin treatment of mammalian cells that had been contaminated with mycoplasmas permitted specific inactivation of mycoplasmas without significantly damaging effects on cell metabolism in the culture (Vollenbroich et al., 1997b). In a more recent study, surfactin was used to eliminate mycoplasma from an extensively infected irreplaceable hybridoma cell line (Kumar et al., 2007). There were apparent indications of limited elimination, suggesting the possible use of surfactin in achieving total decontamination. However, it was observed that surfactin was toxic to the infected hybridoma cells plated at various cell densities and exposure times, therefore it was suggested that preliminary tests should be carried out to determine the cytotoxicity of surfactin before use in decontamination.

Another study confirmed surfactin potential to eliminate mycoplasma cells independently of the target cell, which is a significant advantage over the mode of action of conventional antibiotics (Fassi et al., 2007). This study also reported that surfactin exhibited a synergistic effect in combination with enrofloxacin, and resulted in mycoplasma-killing activity of about two orders of magnitude greater than when the molecules were used separately.

\subsubsection{Antifungal activity}

The antifungal activities of biosurfactants have long been known, although their action against human pathogenic fungi has been rarely described (Abalos et al., 2001; Chung et al., 
2000; Tanaka et al., 1997). The previously mentioned cellobiose lipid flocculosin isolated from Pseudozyma flocculosa, was shown to display in vitro antifungal activity against several pathogenic yeasts, associated with human mycoses, including Candida lusitaniae, Cryptococcus neoformans, Trichosporon asahii and Candida albicans (Mimee et al., 2005). This product positively inhibited all pathogenic strains tested under acidic conditions and showed synergistic activity with amphotericin B. Moreover, no significant cytotoxicity was detected when tested against human cell lines. In nature, flocculosin is part of $P$. flocculosa biocontrol arsenal against other fungi. Recent reports however have suggested that flocculosin is also used by $P$. flocculosa as a nutrient source when experiencing food limitation and the molecule is rapidly deacylated under alkaline conditions losing its antimicrobial activity which may explain conflicting results concerning the antimicrobial activity of this class of glycolipids (Mimee et al., 2009).

Other antifungal activity of biosurfactants against phytopathogenic fungi has also been described. It has been recently demonstrated that glycolipids, such as cellobiose lipids (Kulakovskaya et al., 2009, 2010) and rhamnolipids (Debode et al., 2007, Banat et al, 2010) and cyclic lipopeptides (Tran et al., 2007, 2008, as cited in Banat et al, 2010), including surfactin, iturin and fengycin (Kim et al., 2010; Arguelles-Arias et al., 2009, Chen et al., 2009, Grover et al., 2010, Mohammadipour et al., 2009, Snook et al., 2009) can all have varying degrees of antimicrobial activities.

\subsection{Antiadhesion activity of biosurfactants}

Microbial biofilms formation on medical and technical equipment is an important and mostly hazardous occurrence, especially as the bacteria within such biofilms usually become highly resistant to antibiotics and adverse environmental challenges. Several approaches have been adopted in order to limit pathogen colonization. Strict hygienic practices by healthcare personnel such as hand washing and regular disinfection of equipment and environment become of grave importance. However, it should be noted that routine disinfection is becoming controversial as frequent application becomes less effective (Dettenkofer et al., 2004, 2007, Kramer et al., 2006, as cited in Falagas \& Makris, 2009).

\subsubsection{Biofilms on medical devices}

Device-related infections are often identified as having a biofilm aetiology and biofilm formation can occasionally be facilitated by the host inflammatory response molecules which can make adhesion to the surface of the device easier (Hall-Stoodley et al., 2004). Almost all kind of surfaces are suitable to be colonized by biofilms (Donlan \& Costerton, 2002). Biomedical devices are not the exception, biofilms are often found on the surface of urinary catheters (Stickler, 2008), central venous catheters (Petrelli et al., 2006), heart valves (Litzler et al., 2007), voice prostheses (Buijssen et al., 2007), contact lenses (Imamura et al., 2008), hip prostheses (Dempsey et al., 2007) and intrauterine devices (Chassot et al., 2008).

Current biofilm preventive strategies are essentially aimed at coating medical surfaces with antimicrobial agents, a process not always successful (Basak et al., 2009; von Eiff et al., 2005). Bacteria in biofilms become highly resistant to antibiotics, and so they evade host defenses withstanding antimicrobial chemotherapy (Morikawa, 2006). Since nosocomial infections remain an important problem even for hospitals with strict infection control programmes, infection control measures remain highly sought after (Falagas \& Makris, 2009). Development of successful technologies based on the biofilm formation and growth control is expected to be a major breakthrough in the clinical practice and preventive medicine. 
To eliminate biofilm formation novel compounds capable of specifically targeting biofilm growth while causing no adverse toxicity to the environment of application are needed. Several reports have suggested that, in addition to their direct action against pathogens, biosurfactants are able to interfere with biofilm formation, modulating microbial interaction with interfaces (Federle \& Bassler 2003; Merk et al., 2005; Neu, 1996; Rasmussen \& Givskov, 2006; Rodrigues et al., 2006b, 2006c; Rodrigues et al., 2007).

Surfactin for example has shown to be an important part of a list of biofilm controlling agents. Surfactin is able to inhibit biofilm formation of Salmonella typhimurium, S. enterica, E. coli and Proteus mirabilis in polyvinyl chloride wells, as well as vinyl urethral catheters (Mireles et al., 2001). Many Salmonella species are important opportunistic pathogens of the urinary tract system. Recently, two lipopeptide biosurfactants, produced by B. subtilis V9T14 and B. licheniformis V19T21, showed the ability to selectively inhibit biofilm formation by pathogenic strains on polystyrene (Rivardo et al., 2009). In particular, S. aureus ATCC 29213 and E. coli CFT073 biofilm formation were decreased by $97 \%$ and 90\%, respectively. V9T14 biosurfactant was active on the Gram-negative strain yet ineffective against the Grampositive while the opposite was observed for V19T21 biosurfactant. These effect were observed either by coating the polystyrene surface with these compounds or by adding the biosurfactant to the inoculum. The chemical characterization of V9T14 lipopeptide biosurfactant carried out by LC/ESI-MS/MS revealed that it was composed of $77 \%$ of surfactin and of $23 \%$ of fengycin (Pecci et al., 2010).

The activity of $\mathrm{AgNO}_{3}$ combined with the lipopeptide biosurfactant V9T14 has also been studied against a preformed E. coli biofilm on the Calgary Biofilm device (Rivardo et al., 2010). Results indicated that the activity of silver can be synergistically enhanced by the presence of V9T14, allowing a reduction in the quantity of silver used to achieve greater antimicrobial impact. The concentrations of silver in the silver-biosurfactant solutions were 129 to 258 fold less than the concentrations needed when silver was used alone. In another study, the V9T14 biosurfactant in association with antibiotics led to a synergistic increase in the efficacy of antibiotics in E. coli CFT073 biofilm innhibition and, in some combinations, to total eradication of the uropathogenic strain biofilm (Rivardo et al., 2011).

In another recent work, marine bacterial culture supernatants of Bacillus pumilus and B. indicus significantly inhibited the initial attachment process and biofilm formation and dispersal of mature biofilms of Vibrio spp. strains (Nithya \& Pandian, 2010). The bacterial supernatants also reduced the surface hydrophobicity of Vibrio spp. which is one of the important requirements for biofilm development. Valle et al., (2006) observed that distinct serotypes of group II capsular polysaccharides, produced by the uropathogenic E. coli (UPEC strain CFT073) behaved like surface-active polymers that displayed anti-adhesion properties. The treatment of abiotic surfaces with group II capsular polysaccharides drastically reduced both initial adhesion and biofilm development of important nosocomial pathogens.

More recently, the effect of different temperatures on the anti-adhesive activity of surfactin and rhamnolipid biosurfactants was tested on polystyrene surfaces, regarding the attachment of Staphylococcus aureus, Listeria monocytogenes, and Micrococcus luteus (Zeraik \& Nitschke, 2010). Surfactin inhibited bacterial adhesion at all tested conditions, and its activity increased with the decrease in temperature, giving a $63-66 \%$ adhesion reduction in the bacterial strains at $4^{\circ} \mathrm{C}$. Rhamnolipids promoted a slight decrease in the attachment of $S$. aureus but were not as effective. The ability of rhamnolipid biosurfactant to inhibit adhesion of microorganisms to silicone rubber was also investigated in a parallel-plate flow chamber (Rodrigues et al., 2006c). The results showed an effective reduction in the initial deposition 
rates and in the number of bacterial cells adhering after $4 \mathrm{~h}$, for several microorganisms. Moreover, perfusing the flow chamber with biosurfactant containing solution followed by the passage of a liquid-air interface produced high detachment $(96 \%)$ of adhered cells for several microorganisms. These capabilites have a lot of implications regarding biofilm formation and microbial contamination and establishments on such biomedical devices made of such compounds.

Antibiofilm activity was also reported for a glycolipid biosurfactant isolated from another marine bacterium Brevibacterium casei MSA19 against pathogenic biofilms in vitro (Kiran et al., 2010a). The purified glycolipid disrupted the biofilm formation under dynamic conditions and the biofilm-forming capacity of both mixed culture and individual human and fish pathogenic strains was significantly inhibited at $30 \mathrm{mg} / \mathrm{mL}$ glycolipid. Raya et al., (2010) analyzed the effects of rhamnolipids and shear on initial attachment of Pseudomonas aeruginosa PAO1 in glass flow chambers. The presence of rhamnolipids significantly reduced the initial attachment of PAO1, even at the low concentration of $13 \mathrm{mg} / \mathrm{L}$. Prewashing the cells with a $100 \mathrm{mg} / \mathrm{L}$ rhamnolipid solution, however, did not affect the attachment significantly. The initial cell attachment increased with increasing shear at the very low shear range (up to $3.5-5.0 \mathrm{mN} / \mathrm{m}^{2}$ ), however the attachment could be minimized with further increase of the shear.

The biosurfactant Lunasan produced by the yeast Candida sphaerica UCP0995 completely inhibited the adhesion of Streptococcus agalactiae, Streptococcus sanguis 12, Streptococcus mutans, Streptococcus mutans NS, Staphylococus epidermidis, Staphylococus aureus and Candida albicans on plastic tissue culture plates at a concentration of $10 \mathrm{mg} / \mathrm{ml}$ and $\approx 92 \%$ inhibition of adhesion occurred for Pseudomonas aeruginosa (Luna et al., 2011). Lunasan, tested at the same concentration, also showed antimicrobial activity against the strains Streptococcus oralis $(68 \%)$, Candida albicans (57\%), and Staphylococcus epidermidis (57.6\%). The same research group also described antiadhesive and antimicrobial activities of Rufisan, a biosurfactant produced by the yeast Candida lipolytica UCP 0988 (Rufino et al., 2011). Crude biosurfactant showed antiadhesive activity at $\geq 0.75 \mathrm{mg} / \mathrm{L}$ against most of the microorganisms tested (Staphylococus aureus, Streptococcus agalactiae, Streptococcus mutans NS) and the anti-adhesive property was proportional to the concentration of the biosurfactant while antimicrobial activities were also observed at higher biosurfactant concentrations.

In conclusion, the anti-adhesive activity of biosurfactants against several pathogens indicates their potential utility as coating agents for medical insertional materials that may lead to a reduction in a large number of hospital infections without the need for use of synthetic drugs and chemicals.

\subsubsection{Biofilms on food processing surfaces}

In addition to the treatment of biomaterials used for medical devices, biosurfactants have also been used in the pre-treatment of material surfaces found in food-processing environments. Pathogenic bacteria implicated in food-borne illness outbreaks are able to form biofilms on food contact surfaces that are more resistant to sanitation than free-living cells (Kalmokoff et al., 2001; Kim et al., 2006; Stepanovic et al., 2004). The pre-conditioning of surfaces using microbial surface-active compounds may be an interesting strategy for preventing the adhesion of food-borne pathogens to solid surfaces. Meylheuc et al., (2006b) demonstrated that the preconditioning of stainless steel surfaces with an anionic biosurfactant produced by Pseudomonas fluorescens reduced the number of L. monocytogenes LO28-adhering cells and thus favoured the bactericidal activities of the disinfectants sodium hypochlorite $(\mathrm{NaOCl})$ and peracetic acid/hydrogen peroxide $(\mathrm{PAH})$. 
Similarly, biosurfactants obtained from Lactobacillus helveticus and P. fluorescens were able to inhibit the adhesion of four Listeria strains to stainless steel (Meylheuc et al., 2006a). Whichever strain of L. monocytogenes used in combination with biosurfactants, the antiadhesive biological coating developed both reduced the total adhering flora and the viable and culturable adherent bacteria on stainless steel surfaces. More recently, another group investigated the effect of rhamnolipid and surfactin biosurfactants on the adhesion of the food pathogens E. sakazakii, L. monocytogenes and S. enteritidis to polypropylene and stainless steel surfaces (Nitschke et al., 2009). Preconditioning with surfactin, rather than rhamnolipid, caused a reduction in the number of adhering cells particularly of $L$. monocytogenes and to some extent E. sakazakii on stainless steel. Surfactin showed a significant decrease in the adhesion on polypropylene of all strains. The adsorption of surfactin on polystyrene also reduced the adhesion of S. enteritidis- and L. monocytogenesgrowing cells. In addition, surfactin was able to delay bacterial adhesion within short contact periods using non-growing cells or longer contact periods using growing cells.

Other antimicrobial and antiadhesive properties of a biosurfactant produced by Lactobacillus paracasei ssp. paracasei A20 isolated from a Portuguese dairy plant were also described (Gudiña et al., 2010). The biosurfactant had antimicrobial activity against a broad range of microorganisms including the pathogenic C. albicans, E. coli, S. aureus, S. epidermidis and Streptococcus agalactiae while exhibiting a considerable antiadhesive activity against a wide range of microorganisms.

The activity demonstrated by biosurfactants suggests that they could be considered as new tools in developing strategies to prevent or delay microbiological colonization of industrial plant surfaces used in foodstuffs preparation.

\subsection{Probiotics biosurfactants activity}

Probiotics are: "Live microorganisms which when administered in adequate amounts confer a health benefit on the host". They have been reported to have positive effects on the maintenance of human health (Gupta \& Garg 2009). Interest in probiotics has gained great significance due to the increasing antimicrobial resistance of bacteria worldwide. Evidence suggests that probiotic organisms may have a role in lowering the incidence or the duration of antibiotic-related diarrhea, contributing to the prevention or treatment of vaginal candidiasis, bacterial vaginosis and recurrent lower urinary tract infections. Furthermore, they encourage improved immunological defense responses and can decrease the activity of numerous toxic antimetabolites (Falagas et al., 2006a, 2006b, 2007).

Probiotics mechanisms of action vary, however, some are known to produce various antimicrobial agents such as organic acids, hydrogen peroxide, carbon peroxide, diacetyl, low molecular weight antimicrobial substances and bacteriocins (Merk et al., 2005). In addition, probiotics have long been known also for the capacity to interfere with the adhesion and formation of biofilms of pathogens to epithelial cells of urogenital and intestinal tracts (Reid et al., 1998, 2001). The mechanisms of this interference include the release of surface active molecules (Gudiña et al., 2010; Rodrigues et al., 2006d). Hong et al., (2005) reported the production of antimicrobial lipopeptides by Bacillus probiotics products as the main mechanisms by which they inhibit the growth of pathogenic microorganisms in the gastrointestinal tract. Similarly, competition with other microorganisms for adherence to epithelial cells as well as biosurfactants production are well known mechanisms used by Lactobacillus probiotics to interfere with vaginal pathogens (Barrons \& Tassone, 2008; Cribby et al., 2008; Falagas et al., 2007). 
Several investigators have pointed to evidence that probiotic type microorganisms and their biosurfactants may antagonize the growth of nosocomial pathogens on inanimate surfaces (Rodrigues et al., 2004a, 2004b, 2006b, 2006c; Walencka et al., 2008). Falagas \& Makris, (2009) reviewed studies involving in vitro experiments on the potential role of probiotics microorganisms and their products in the inhibition of bacterial or fungal colonisation of artificial surfaces, such as vinyl urethral catheters and silicon rubber voice prostheses (Busscher et al., 1997, 1998; Velraeds et al., 1996, 1997, 2000; Rodrigues et al., 2004a, 2004b, 2006b, Van der Mei et al., 2000). The majority of the investigators examined the preconditioning of the materials surfaces with probiotic biosurfactants, while others added probiotic biosurfactant producing strains to examin adhesion or biofilm development. It was generally demonstrated that both probiotics microorganisms alone (mainly Streptococcus thermophilus and Lactobacillus spp. strains) or their biosurfactants were able to antagonize growth and development of potentially pathogenic microorganisms including Staphylococcus aureus, Staphylococcus epidermidis, Streptococcus spp., Enterococcus faecalis, Candida albicans, Candida tropicalis (Busscher et al., 1997; Van Hoogmoed et al., 2000).

Rodrigues et al., (2004a) demonstrated that the biosurfactant obtained from the probiotic bacterium Lactococcus lactis 53 was able to inhibit the adhesion of bacterial pathogens to silicone rubber with an adsorbed biosurfactant layer. Adhesion of yeasts was also decreased in the presence of biosurfactant, but to a lesser extent. In another work, using an artificial throat model, the same authors showed that biosurfactants obtained from probiotic strains greatly reduced microbial numbers on voice prostheses and induced a decrease in the airflow resistance of voice prostheses after biofilm formation, which may prolong the lifetime of indwelling silicone rubber voice prostheses (Rodrigues et al., 2004b).

In a more recent work, it was demonstrated that the preconditioning of silicon rubber with a biosurfactant produced by the strain Streptococcus thermophilus A reduced adhering bacterial pathogens by up to $97 \%$ and adhering Candida spp. by up to $70 \%$ (Rodrigues et al., 2006b). Velraeds et al., (1996) also reported on the inhibition of adhesion of pathogenic enteric bacteria by a biosurfactant produced by a Lactobacillus strain and later showed that the biosurfactant caused an important dose-related inhibition of the initial deposition rate of $E$. coli and other bacteria adherent on both hydrophobic and hydrophilic substrata (Velraeds et al., 1997).

Another interesting application area that is gaining increased interest relates to probiotics use in preventing oral infections (Çaglar et al., 2005; Hatakka et al., 2007; Kõll et al., 2008; Meurman, 2005; Meurman \& Stamatova, 2007). Van Hoogmoed et al., (2004) demonstrated that Streptococcus mitis biosurfactant inhibited adhesion of Streptococcus sobrinus HG 1025 and Streptococcus mutans ATCC 25175 to bare enamel, while S. mitis biosurfactant was able to inhibit the adhesion of S. sobrinus HG 1025 to salivary pellicles. The authors later reported that these reductions may be attributed to increased electrostatic repulsion between the bacteria and the biosurfactant-coated pellicles (Van Hoogmoed et al., 2006).

New biosurfactant molecules produced by probiotic bacteria are reported from dairy products and environment. Recent work by Walencka et al., (2008) demonstrated that surfactants obtained from three Lactobacillus acidophilus strains inhibited S. epidermidis and S. aureus biofilm integrity and formation. Moreover, surfactant addition to preformed mature biofilms accelerated their dispersal and altered the characteristics of the biofilm morphology. A novel xylolipid biosurfactant from Lactococcus lactis, a probiotic strain isolated from a traditional Indian fermented dairy product, showed a good antibacterial activity against clinical pathogens of E. coli and MRSA strains (Saravanakumari \& Mani, 2010). Xylolipid was non-pathogenic and safe for oral consumption and dermal applications, 
suggesting that it could be safely used as a therapeutic agent or as a preservative in food or cosmetic products.

In another recent work, a biosurfactant producing strain, Lactobacillus sp. CV8LAC, isolated from fresh cabbage, showed interesting antiadhesive activity against two C. albicans pathogenic biofilm-producing strains (CA-2894 and DSMZ 11225) (Fracchia et al., 2010). The CV8LAC biosurfactant significantly inhibited the adhesion of fungal pathogens to polystyrene microtiter plates in pre-coating and co-incubation experiments. In pre-coating assays, biofilm formation of strain CA-2894 was reduced by $82 \%$ at concentration of $312.5 \mu \mathrm{g} / \mathrm{mL}$ while that of strain DSMZ 11225 was reduced by $81 \%$ at $625 \mu \mathrm{g} / \mathrm{mL}$. In co-incubation assays, biofilm formation of the two strains was inhibited by $70 \%$ at 160.5 $\mu \mathrm{g} /$ well and by $81 \%$ at $19.95 \mu \mathrm{g} /$ well, respectively. It was interesting to note that no inhibition of both $C$. albicans planktonic cells was observed, thus indicating that the biosurfactant displayed specific anti-biofilm formation but not antimicrobial activity.

Considering their importance for human health and their recognized safety, environmental probiotic organisms may, thus, represent a safe and effective intervention for infection control purposes. Probiotics themselves or their products (biosurfactants), could be applied to patient care equipment, such as tubes or catheters, with the aim of decreasing the colonisation of these sites by nosocomial pathogens and potentially impede a central step in the pathogenesis of nosocomial infections (Falagas \& Makris, 2009).

\subsection{Other promising biological activities}

Biosurfactants have been shown to have many other roles in biomedical application. Some of the most powerful molecules (eg. surfactin, mannosylerythritol lipids (MELs), trehalose lipids) are known to have anti-inflammatory, anti-tumour, immunosuppressive and immunomodulating functions, in addition to other properties such as self-assembling, human cells stimulation and differentiation, interaction with stratum corneum lipids, cell-tocell signaling, hemolytic activity.

\subsubsection{Anti-tumor activity}

Recently, it has been demonstrated that these interesting microbial products can control a variety of mammalian cell functions. They are considered to participate in various intercellular molecular recognitions such as signal transduction, cell differentiation, cell immune response, etc. (Osada, 1998). Cao et al., (2010) demonstrated that surfactin induces apoptosis in human breast cancer MCF-7 cells through a ROS/JNK-mediated mitochondrial/caspase pathway. In a more recent work, they investigated the reactive oxygen species (ROS) and $\mathrm{Ca}^{2+}$ impact on mitochondria permeability transition pore (MPTP) activity, and MCF-7 cell apoptosis induced by surfactin (Cao et al., 2011). The results showed that surfactin initially induced the ROS formation, leading to the MPTP opening accompanied with the collapse of mitochondrial membrane potential which lead to an increase in the cytoplasmic $\mathrm{Ca}^{2+}$ concentration. In addition, cytochrome $\mathrm{c}$ was released from mitochondria to cytoplasm through the MPTP which activated caspase-9, eventually inducing apoptosis.

In another study, viscosin, an effective surface-active cyclic lipopeptide recovered from Pseudomonas libanensis M9-3, inhibited the migration of the metastatic prostate cancer cell line, PC-3M, without visible toxicity effects (Saini et al., 2008). More recently, lipopeptides (namely isoforms of surfactins and fengycins) derived from a marine Bacillus circulans DMS- 
2 showed interesting cytotoxic activity against cancer cell lines (Sivapathasekaran et al., 2010). The purified lipopeptides at a concentration of $300 \mu \mathrm{g} / \mathrm{mL}$ showed more than $90 \%$ inhibition of proliferation on both colon cancer cell lines HCT 15 and HT 29 after $24 \mathrm{~h}$ treatment and the antiproliferative activity of lipopeptides was observed in a dose dependent manner.

Significant effects against both tumor cell lines as compared to non-tumor cell line were also observed, thus indicating the selective inhibitory activity of these molecules. Serratamolide AT514, cyclic depsipeptide from Serratia marcescens, belonging to the group of serrawettins, has also been reported to be a potent inducer of apoptosis of several cell lines derived from various human tumors and B-chronic lymphocytic leukemia cells, primarily involving the mitochondria-mediated apoptotic pathway and interference with Akt/NF-kB survival signals (Escobar-Díaz et al., 2005, as cited in Matsuyama et al., 2010). Biological studies of AT514 using human B-lymphocytes are now in progress for clinical applications of AT514 in the field of medical oncology.

Interesting anti-tumor activities has also been reported for glycolipids. Mannosylerythritol lipids (MELs) are among the most promising biosurfactants known due to their versatile interfacial and biochemical actions. Interesting studies, thoroughly reviewed by Kitamoto et al. (2002) and by Arutchelvi \& Doble, (2010), have shown that MEL-A and MEL-B display excellent growth inhibition and differentiation-inducing activities against human leukemia cells including myelogenous leukemia cell K562, promyelocytic leukemia cell HL60, and the human basophilic leukemia cell line KU812, as well as growth inhibition activity of mouse melanoma B 16 cells. Recently Chen et al., (2006) also demonstrated that a sophorolipid produced from the yeast Wickerhamiella domercqiae induced apoptosis in H7402 human liver cancer cells by blocking cell cycle at G1 phase and partly at S phase, activating caspase-3, and increasing $\mathrm{Ca}^{2+}$ concentration in cytoplasm.

\subsubsection{Anti-inflamatory activity}

Byeon et al., (2008) observed that surfactin was able to downregulate LPS-induced nitric oxide production in RAW264.7 cells and primary macrophages by inhibiting NF-KB activation, suggesting a good potential as a bacterium-derived anti-inflammatory agent. Selvam et al., (2009) studied the effect of B. subtilis PB6, a natural probiotic, on plasma cytokine levels in inflammatory bowel disease and colon mucosal inflammation. The strain was found to secrete surfactins which are known to inhibit phospholipase A2, involved in the pathophysiology of inflammatory bowel disease. In animal experiments carried out in rat models for trinitrobenzene sulfonic acid-induced colitis, oral administration of PB6 as a probiotic suppressed colitis as measured by mortality rate and changes in colon morphology and weight gain. Plasma levels of pro-inflammatory cytokines were also significantly lowered and the anti-inflammatory cytokine significantly increased after the oral administration of PB6, supporting the concept that PB6 inhibits PLA2 by secreting surfactins.

In another work, surfactin isomers derived from the mangrove bacterium Bacillus sp. (No. 061341) showed interesting anti-inflammatory activities (Tang et al., 2010). In particular, this class of cyclic lipopeptide showed strong inhibitory properties on the overproduction of nitric oxide and the release of IL-6 in LPS-induced murine macrophage cell RAW264.7. Moreover, structure-activity relationship studies revealed that the existence of the free carboxyl group in the structure of surfactin isomer was crucial as to the anti-inflammatory activities. An interesting recent study explored the mechanisms responsible for surfactininduced anti-inflammatory actions in the context of periodontitis caused by Porphyromonas 
gingivalis, the major pathogen of periodontal disease (Park et al., 2010). The Authors observed that surfactin significantly reduces pro-inflammatory cytokines, including tumor necrosis factor- $\alpha$, interleukin (IL)-1 $\beta$, IL-6, and IL-12, through suppression of nuclear factor$\mathrm{KB}$ activity in $P$. gingivalis LPS-stimulated THP-1 human macrophage cells, in a Heme oxygenase-1 (HO-1)-dependent fashion. Furthermore, surfactin treatment effectively induces HO-1 expression, a major defense in response to oxidative stress.

These observations support the potential of surfactin as a candidate in strategies to prevent caries, periodontitis, or other inflammatory diseases.

\subsubsection{Immuno-modulatory action}

Park \& Kim, (2009) studied the role of surfactin in the inhibition of the immunostimulatory function of macrophages through blocking the NK-kB, MAPK and Akt pathway. This provided a new insight into the immunopharmacological role of surfactin in autoimmune disease and transplantation. Their work indicated that surfactin has potent immunosuppressive capabilities which suggested important therapeutic implications for transplantation and autoimmune diseases, including allergy, arthritis and diabetes.

A biosurfactant glycolipid complex from Rhodococcus ruber was also shown to activate the production of IL-1beta and TNF-alpha cytokines without modifying the production of IL-6, thus suggesting good prospects for further studies of immunomodulating and antitumor activities (Kuyukina et al., 2007).

\subsubsection{Other biomedical related properties}

Han et al., (2008) observed that high surfactin micelle concentration affected the aggregation of amyloid $\beta$-peptide (A $\beta$ (1-40)) into fibrils, a key pathological process associated with Alzheimer's disease. Fengycin, another lipopeptide biosurfactant is also able to cause membrane perturbations (Deleu et al., 2008). Recent results by Eeman et al., (2009) emphasized the ability of fengycin to interact with the lipid constituents of the stratum corneum extracellular matrix and with cholesterol. Another interesting property of surfactin and its synthetic analogues is the ability to alter the nanoscale organisation of supported bilayers and to induce nanoripple structures with intriguing perspectives for biomedical and biotechnological applications (Bouffioux et al., 2007; Brasseur et al., 2007; Francius et al., 2008).

Morita et al., (2010) investigated the cell activating property of MELs using cultured fibroblast and papilla cells, and a three dimensional cultured human skin model. The diacetylated MEL (MEL-A) produced from soybean oil significantly increased the viability of the fibroblast and of the papilla cells over $150 \%$ compared with that of control cells, suggesting potential use as new hair growth agent stimulating the papilla cells. Using a three-dimensional cultured human skin model, Morita et al., (2009b) observed that the viability of the SDS damaged cells was markedly improved by the addition of MEL-A in a dose-dependent manner. This demonstrated that MEL-A also had a ceramide-like moisturising activity toward the skin cells. Similarly, (Kitagawa et al., 2007, as cited in Worakitkanchanakul et al., 2008) reported that MEL-B shows excellent moisturizing properties, equivalent to those of natural ceramides, toward human skin.

Trehalose lipids also display various interesting biological activities mainly due to their great tendency to partition into phospholipid membranes (Ortiz et al., 2008, 2009). In particular, the trehalose lipid was suggested to incorporate into the membrane bilayers and produce structural perturbations, which might affect the function of both phosphatidylethanolamine and phosphatidylserine membranes. Zaragoza et al., (2010) observed that a succinoyl trehalose 
lipid produced by Rhodococcus sp. caused the swelling of human erythrocytes followed by hemolysis at concentrations well below its critical micellar concentration. They concluded that trehalose lipid caused the hemolysis of human erythrocytes by a colloid-osmotic mechanism, most likely by formation of enhanced permeability domains, or "pores" enriched with biosurfactant, within the erythrocyte membrane.

Permealization of biological and artificial membranes was also reported to be induced by Pseudomonas aeruginosa dirhamnolipid (Sánchez et al., 2010). In particular, it caused the hemolysis of human erythrocytes through a lytic mechanism, as shown by the similar rates of $\mathrm{K}^{+}$and hemoglobin leakage, and by the absence of effect of osmotic protectants. Scanning electron microscopy showed that the addition of the biosurfactant changed the usual disc shape of erythrocytes into that of spheroechinocytes.

\section{Biotechnological and nanotechnological applications of surface-active compounds}

Biosurfactants, have been increasingly attracting attention in the field of nanotechnology (Kitamoto et al., 2005, 2009). During the last decade, unique properties of biosurfactants, like versatile self-assembling and biochemical properties, which are not usually observed in conventional chemical surfactants, have been reported (Kitamoto et al., 2005, 2009). In recent years, the development of new functional structures and/or systems using selfassembly of amphiphilic molecules has evolved into a dynamic and rapidly growing area of nanotechnology (Ariga et al., 2007, Shimizu et al., 2005, as cited in Kitamoto et al., 2009) due to their ability to self-assemble into hierarchically ordered structures using hydrogen bonding, hydrophobic and van der Waals interactions as mentiond earlier.

Mannosylerythritol lipids (MELs) show the most interesting self-assembling properties and numerous related potential applications (Kitamoto et al., 2009). Konishi et al., (2007), Imura et al., (2007, 2008), and Ito et al., (2007), for example, developed and studied the kinetics of interactions in carbohydrate ligand systems composed of self-assembled monolayers of mannosylerythritol lipid-A (MEL-A) serving as a high-affinity, easy to handle and low-cost ligand system for immunoglobulin $\mathrm{G}$ and $\mathrm{M}$ and lectins..

Table 1 below lists the latest discoveries in the biotechnological and nanotechnological fields applicable to biosurfactants, and in particular the latest successful results of mannosylerythritol lipids (MELs) application in the enhancement of the gene transfection efficiency of cationic liposomes as well as some interesting applications of glycolipids and other biosurfactants in drug delivery and gene therapy. Biosurfactants use as a "green" alternative for high-performance nanomaterials production and, in particular, for the synthesis and stabilization of metal-bound nanoparticles will also be described.

\begin{tabular}{|c|c|c|}
\hline Biosurfactant type & Activity/application & Study \\
\hline \multirow[t]{3}{*}{$\begin{array}{l}\text { Mannosylerythritol } \\
\text { lipids-A }\end{array}$} & $\begin{array}{l}\text { Ligand system for immunoglobulin } G \\
\text { and } M \text { and lectins }\end{array}$ & $\begin{array}{l}\text { Konishi et al., (2007); } \\
\text { Imura et al., (2007, 2008), } \\
\text { Ito et al., (2007) }\end{array}$ \\
\hline & $\begin{array}{l}\text { DNA capsulation and membrane } \\
\text { fusion with anionic liposomes }\end{array}$ & Ueno et al., (2007a) \\
\hline & $\begin{array}{l}\text { In vitro promotion of gene transfection } \\
\text { mediated by cationic liposomes }\end{array}$ & $\begin{array}{l}\text { Inoh et al., (2001, 2004, } \\
\text { 2010); Igarashi et al., } \\
\text { (2006); Ueno et al., (2007b) }\end{array}$ \\
\hline
\end{tabular}




\begin{tabular}{|c|c|c|}
\hline Biosurfactant type & Activity/application & Study \\
\hline \multirow{8}{*}{$\begin{array}{l}\text { Mannosylerythritol } \\
\text { lipids-B } \\
\text { Rhamnolipids and } \\
\text { sophorolipids }\end{array}$} & $\begin{array}{l}\text { In vivo promotion of liposome- } \\
\text { mediated gene transfection }\end{array}$ & Inoh et al., (2009) \\
\hline & $\begin{array}{l}\text { Herpes simplex virus thymidine } \\
\text { kinase gene therapy }\end{array}$ & Maitani et al., (2006) \\
\hline & Water-in-oil microemulsions & $\begin{array}{l}\text { Worakitkanchanakul et al., } \\
\text { (2008) }\end{array}$ \\
\hline & $\begin{array}{l}\text { Increase membrane fluidity of } \\
\text { monolayers composed of L-a- } \\
\text { dipalmitoylphosphatidylcholine } \\
\text { (DPPC) }\end{array}$ & Kitamoto et al., (2009) \\
\hline & $\begin{array}{l}\text { Self-assembling and vesicle-forming } \\
\text { activity }\end{array}$ & $\begin{array}{l}\text { Worakitkanchanakul et al., } \\
\text { (2008) }\end{array}$ \\
\hline & $\begin{array}{l}\text { Deuterated rhamnolipids and } \\
\text { sophorolipids }\end{array}$ & Smyth et al., (2010b) \\
\hline & Cadmium sulfide nanoparticles & Singh et al., (2011) \\
\hline & $\begin{array}{l}\text { Biocompatible microemulsions of } \\
\text { lecithin/rhamnolipid/sophorolipid } \\
\text { biosurfactants }\end{array}$ & Nguyen et al., (2010) \\
\hline \multirow[t]{6}{*}{ Rhamnolipids } & $\begin{array}{l}\text { Silver nanoparticles with } \\
\text { antibioticmicrobial activity }\end{array}$ & Kumar et al., (2010) \\
\hline & $\begin{array}{l}\text { Nickel oxide nanoparticles by } \\
\text { microemulsion technique }\end{array}$ & $\begin{array}{l}\text { Palanisamy \& Raichur, } \\
\text { (2009) }\end{array}$ \\
\hline & Silver nanoparticles & Xie et al., (2006) \\
\hline & ZnS nanoparticles & Narayanan et al., (2010) \\
\hline & Microemulsions & Xie et al., $(2005,2007)$ \\
\hline & Alcohol-free microemulsions & Nguyen \& Sabatini, (2009) \\
\hline \multirow[t]{4}{*}{ Sophorolipids } & Cobalt nanoparticles & Kasture et al., (2007) \\
\hline & Silver nanoparticles & Kasture et al., (2008) \\
\hline & $\begin{array}{l}\text { Sophorolipid-coated silver and gold } \\
\text { nanoparticles with antibacterial } \\
\text { activity }\end{array}$ & Singh et al., $(2009,2010)$ \\
\hline & $\begin{array}{l}\text { Biocompatible microemulsions of } \\
\text { lecithin/rhamnolipid/sophorolipid } \\
\text { biosurfactants }\end{array}$ & Nguyen et al., (2010) \\
\hline $\begin{array}{l}\text { Glycolipid } \\
\text { biosurfactant }\end{array}$ & Silver nanoparticles & Kiran et al., (2010b) \\
\hline $\begin{array}{l}\text { Fengycin and } \\
\text { surfactin }\end{array}$ & $\begin{array}{l}\text { Enhancers for the skin accumulation } \\
\text { of aciclovir }\end{array}$ & Nicoli et al., (2010) \\
\hline \multirow[t]{2}{*}{ Surfactin } & $\begin{array}{l}\text { Surfactin-mediated synthesis of gold } \\
\text { nanoparticles }\end{array}$ & Reddy et al., (2009) \\
\hline & Cadmium sulfide nanoparticles & Singh et al., (2011) \\
\hline
\end{tabular}

Table 1. Examples of recent biosurfactant applications in the biotechnological and nanotechnological fields. 


\subsection{Liposomes and gene transfection}

Gene transfection into the cells is a fundamental technology not only for molecular and cellular biology processes but also a clinical gene therapy (Ueno et al., 2007b). Although several methods for gene transfection have been investigated (Felgner et al., 1989, Fujiwara, 2000, Gao \& Huang, 1991, Hatakeyama et al., 2007, Nishiyama et al., 2005, Ueno et al., 2007b), more efficient and safe systems are still needed (Ueno et al., 2007b). Among the various methods, lipofection using cationic liposomes is considered to be a promising method for introducing foreign gene to the targeted cells due to their high transfection efficiency, low toxicity and immunogenicity, ease of preparation and targeted application (Farhood et al., 1992, Felgner et al., 1989, Kogure et al., 2007, Lasic, 1998, Nakanishi, 2003, Inoh et al., 2010). The physicochemical properties of cationic liposomes, such as lipid packing density, shape, and zeta-potential, have a significant effect on gene transfection efficiency (Lin et al., 2003, Takeuchi et al., 1996, Wittenberg et al., 2008, Xu et al., 1999, as cited by Inoh et al., 2010).

Inoh et al., (2001) reported that MEL-A promoted DNA transfection efficiency mediated by cationic liposomes. Confocal laser scanning microscopic analysis showed the distribution of lipids and oligonucleotide DNA in MEL-A-containing liposome-DNA complex in the plasma membrane and the nucleus of target cells at $1 \mathrm{~h}$ after the addition of complex (Inoh et al., 2004). This suggests that MEL-A induces the membrane fusion between the target cells and the cationic liposomes, accelerating the efficiency of gene transfection significantly. Similarly, Igarashi et al., (2006) reported that MEL-A significantly increased the cellular association and the efficiency of gene transfection mediated by cationic liposomes in human cervix carcinoma Hela cells. Analysis of flow cytometric profiles clearly indicated that the amount of DNA associated with the cells was rapidly increased and sustained by addition of MEL-A to the liposome. Confocal microscopic observation also indicated that the MELlipoplex distributed widely in the cytoplasm and DNA presence was intensely detected in cytoplasm around the nucleus.

The above results suggested that MEL-A increased gene expression by enhancing the association of the lipoplexes with the cells in serum and, thus, MEL-liposome may prove a significant nonviral vector for gene transfection and gene therapy.

In an attempt to explain how MEL-A-containing liposomes could accelerate gene transfection, Ueno et al., (2007a) examined MEL-containing liposomes properties such as their activity for DNA capsulation and membrane fusion abilities of cationic liposomes with artificial anionic liposomes. They observed that MEL-A-containing liposomes exhibited high activity in DNA incapsulation and membrane fusion with anionic liposomes, which are important properties for gene transfection. On the other hand, MEL-B- and MEL-Ccontaining liposomes only increased either the incapsulation or the membrane fusion. Ueno et al., (2007b) further examined the mechanism of the transfection mediated by cationic liposomes with NBD-conjugated MEL-A and reported that MEL-A distributed on the intracellular membranes through the plasma membranes of target cells, while the cationic liposomes with MEL-A fused to the plasma membranes within 20-35 min. Thereafter, they noted that the oligonucleotide released from the vesicles was immediately transferred to the nucleus. They therefore suggested that MEL-A was capable of promoting the transfection efficiency of target cells by inducing membrane fusion between liposomes and the plasma membrane of these cells.

Recently Kitamoto et al., (2009) demonstrated that monolayers composed of L-adipalmitoylphosphatidylcholine (DPPC) containing MEL-A had greater membrane fluidity 
than those containing only DPPC. It was also reported that unsaturated fatty acids in MELA significantly influenced surface pressure and packing density in the monolayer and thus the physicochemical properties of MEL-A and MEL-A/lipids (Imura et al., 2008). Transfection efficiency of nano vectors with MEL-A was investigated in vivo on tumor cells in the mouse abdominal cavity (Inoh et al., 2009). When a complex of the nano vectors with MEL-A and plasmid DNA was injected intraperitoneally into C57BL/6J mice bearing B16/BL6 tumors, the biosurfactant significantly increased liposome-mediated gene transfection to the mouse tumor cells. The transfection efficiency of the plasmids into the solid tumors by the cationic liposomes of cholesteryl-3beta-carboxyamidoethylene-Nhydroxyethylamine (OH-Chol) with MEL-A increased by approximatley 100-fold compared to that by the commercially available DC-Chol cationic liposomes without MEL-A. This suggests that nonviral vectors with MEL-A are very useful for gene transfection in vivo. The mechanisms of gene delivery by nano vectors with MEL-A and the numerous biological activities of these biosurfactants have been described by Nakanishi et al., (2009) and Kitamoto et al., (2009).

Inoh et al., (2010) further investigated the effects of unsaturated fatty acid ratio within the MEL-A compound on the physicochemical properties and gene delivery into cells of cationic liposomes using MEL-A with three different unsaturated fatty acid (USF) component ratios. Gene transfer efficiency of cationic liposomes containing MEL-A (containing 21.5\% USF) was much higher than that of those containing MEL-A (containing 9.1\%USF) and MEL-A (containing 46.3\%USF). In particular, MEL-A (21.5\% USF)-containing cationic liposomes induced highly efficient membrane fusion after addition of anionic liposomes and led to subsequent DNA release.

Imaging analysis revealed that MEL-A (21.5\% USF)-containing liposomes fused with the plasma membrane and delivered DNA into the nucleus of NIH-3T3 cells, MEL-A (46.3\% USF)-containing liposomes fused with the plasma membrane did not deliver DNA into the nucleus, and MEL-A (9.1\% USF)-containing liposomes neither fused with the plasma membrane nor delivered DNA into the nucleus. These results suggest that the MEL-A unsaturated fatty acid ratio significantly affects transfection efficiency due to changes in membrane fusion activity and the efficiency of DNA release from the liposomes.

Mannosylerythritol lipid-B (MEL-B) with a different configuration of the erythritol moiety was found to self-assemble into a lamellar phase over remarkably wide concentration and temperature ranges; furthermore it showed great potential as a vesicle-forming lipid, suggesting its potential application in drug and gene delivery as well as in transdermal delivery systems (Worakitkanchanakul et al., 2008). In another work, a liposome vector containing betasitosterol beta-D-glucoside biosurfactant-complexed DNA was successfully used for herpes simplex virus thymidine kinase gene therapy (Maitani et al., 2006).

\subsection{Biosurfactants potential in drug delivery}

Properties such as detergency, emulsification, foaming and dispersion make biosurfactants interesting molecules with potential application in the field of drug delivery (Faivre \& Rosilio, 2010). MEL-A for example has much higher emulsifying activity with soybean oil and tetradecane than polysorbate 80 (Kitamoto et al., 2009) and is able to form stable waterin-oil microemulsions without addition of co-surfactant or salt (Worakitkanchanakul et al., 2008).

Rhamnolipids and sophorolipids have also been mixed with lecithins to prepare biocompatible microemulsions in which the phase behavior was unaffected by changes in 
temperature and electrolyte concentration, making them desirable for cosmetic and drug delivery applications (Nguyen et al., 2010). In 1988, rhamnolipid liposomes were patented as drug delivery systems, useful as microcapsules for drugs, proteins, nucleic acids, dyes and other compounds, as biomimetic models for biological membranes and as sensors for detecting $\mathrm{pH}$ variations. These novel liposomes were described as safe and biologically decomposable, with suitable affinity for biological organisms, stable and with long service and shelf life.

The potential of lipopeptides, fengycin and surfactin to act as enhancers for the transdermal penetration and skin accumulation of aciclovir was also recently investigated (Nicoli et al., 2010) to elucidate any possible synergistic effect between surfactin and fengycin associated with anodal iontophoresis. It was demonstrated that these lipopeptides did not enhance aciclovir transport across the skin (not even when associated with iontophoresis) although they increased aciclovir concentration in the epidermis by a factor of 2 (Nicoli et al., 2010).

Microemulsion produced using biosurfactant are thermodynamically stable and their isotropic systems that form spontaneously-consisting of microdomains of oil or water stabilized by an interfacial film - in addition to their long-term stability, easy preparation and high solubilization capacity are considered to be very promising liquid vehicles for future drug delivery systems (Date et al., 2008, as cited in Faivre \& Rosilio, 2010).

\subsection{Nanoparticles}

Another interesting application for natural surfactant is the the synthesis of metal-bound nanoparticles as an alternative environmentally friendly technology (Sharma et al., 2009). Nanomaterials synthesis and use has been an active research area due to interesting properties of the nanomaterials as compared to bulk material use (Palanisamy \& Raichur, 2009). Metal nanoparticles have beening explored in various fields such as catalysis, mechano- and electrical applications and biomedical uses (Van Bogaert \& Soetaert, 2010). The reduction in size gives rise to size dependent effects such as high surface to volume ratio, lower melting point, changes in electronic structure and changes in lattice structure and interatomic distances which in turn affect the processing parameters (Liveri, 2006, as cited in Palanisamy \& Raichur, 2009).

The use of gold nanoparticles, in particular, is currently undergoing a dramatic expansion in the field of drug and gene delivery, targeted therapy and imaging technologies (Boisselier \& Astruc, 2009; Pissuwan et al., 2009, 2011). Potential therapeutic applications of gold compound and gold nanoparticles also include anti-HIV activity, anti-angiogenesis, antimalarial activity, anti-arthritic activity and biohydrogen production (Kalishwaralal et al., 2010). Silver nanoparticles are also been reported to possess anti-fungal activity, antiinflammatory effect, anti-viral, anti-angiogenesis and anti-platelet activity (Kalishwaralal et al., 2010).

Reddy et al., (2009) successfully synthesized surfactin-mediated gold nanoparticles and investigated the effects of proton concentrations and temperature on the morphology of the obtained nanoparticles. It was demonstrated that the nanoparticles synthesized at $\mathrm{pH} 7$ and 9 remained stable for 2 months, while aggregates were observed at $\mathrm{pH} 5$ within $24 \mathrm{~h}$. Moreover, the nanoparticles formed at $\mathrm{pH} 7$ were uniform in shape and size and were polydispersed and anisotropic at $\mathrm{pH} 5$ and 9. The nanoparticles synthesized produced at room temperature were monodispersed and were more uniform when compared to those formed at $4^{\circ} \mathrm{C}$. More recently they also carried out a biological synthesis of gold and silver 
nanoparticles using the bacteria Bacillus subtilis. Gold nanoparticles were synthesized both intra- and extracellularly, while silver nanoparticles were exclusively formed extracellularly (Reddy et al., 2010). According to the Authors the nanoparticles were stabilized by the surface-active molecules i.e., surfactin or other biomolecules released into the solution by $B$. subtilis.

Surfactin produced by Bacillus amyloliquefaciens KSU-109 was also used for the synthesis of cadmium sulfide nanoparticles which remained stable up to six months without compromising their functionality (Singh et al., 2011). This kind of nanoparticles works as semiconductors with unique optical properties and tunable photo-luminescence allowing potential applications in solar energy conversion, nonlinear optical, photoelectrochemical cells and heterogeneous photocatalysis (Singh et al., 2011). In addition, surfactin produced by strain KSU-109 was easily extracted and used without further purification for nanoparticles stabilization under ambient conditions (Singh et al., 2011). Such simple, inexpensive and environmental friendly procedure of obtaining surfactin offers a further advantage of use in nanobiotechnology for the large-scale production of highly stable metal nanoparticles.

Both rhamnolipids and sophorolipids have also been successfully used for the synthesis and stabilization of metal-bound nanoparticles. Purified rhamnolipids from $P$. aeruginosa strain BS-161R were used to synthesize silver nanoparticles which exhibited good antibiotic activity against both Gram-positive and Gram-negative pathogens and Candida albicans, suggesting their broad spectrum antimicrobial activity (Kumar et al., 2010). In another work, a glycolipid biosurfactant produced from sponge-associated marine bacteria Brevibacterium casei MSA19, using agro-industrial and industrial waste as substrate, were used as a "green" stabilizer for the synthesis of stable and uniform silver nanoparticles (Kiran et al., 2010b). The biosurfactant acted as stabilization agent and prevented the formation of aggregates.

Palanisamy \& Raichur, (2009) also described a simple and eco-friendly method for synthesizing spherical nickel oxide nanoparticles by microemulsion technique using rhamnolipids as alternative surfactant. The synthesized nanoparticles were found to be fully crystalline and spherical in shape with uniform distribution and increasing the $\mathrm{pH}$ of the solution decreased the size of the nanoparticles. Xie et al., (2006) were also able to synthesize silver nanoparticles in rhamnolipid reverse micelles while in another study rhamnolipids were used as capping agents for the synthesis of $\mathrm{ZnS}$ nanoparticles in aqueous medium (Narayanan et al., 2010).

Sophorolipids were also tested for use in nanoparticles synthesis and reported to be good reducing and capping agents for cobalt and silver particles (Kasture et al., 2007, 2008, as cited in Van Bogaert \& Soetaert, 2010). Singh et al., (2009) demonstrated the antibacterial activity of sophorolipid-coated silver and gold nanoparticles against both Gram-positive and -negative bacteria. They also verified that sophorolipid-coated gold nanoparticles were more cyto and geno-compatible with respect to silver nanoparticles (Singh et al., 2010). They also plan to investigate these nanoparticles suitability for medical and diagnostic applications.

Recently, methodologies for the biological synthesis of metal nanoparticles using microbes have also been described (Narayanan \& Sakthivel, 2010; Kalishwaralal et al., 2010; Reddy et al., 2010). In addition Smyth et al., (2010b) reported on the production of selectively deuterated rhamnolipids and sophorolipids using deuterated substrates. The production of such deuterated biosurfactants, in particular, or other bioactive microbial products in general, in which distinct pattern of labeling could be achieved resulting in varing molecular 
weight products and or stereochemistry unrecognised by existing degradative enzymes is very improtant. Such molecules would have great future implications with regards to efficacy and/or persistence or the development of resistance for some bioactives particularly in biomedical related applications.

\subsection{Microemulsions}

Microemulsions are thermodynamically stable, isotropic dispersions of oil, water and surfactant (Rosen, 1989, as cited in Nguyen et al., 2010). Microemulsion systems produce high solubilization capacity and ultralow interfacial tensions of oil and water, making them desirable in practical applications such as enhanced oil recovery, drug delivery, food and cosmetic applications (Bourrel \& Schechter, 1988, Kogan \& Garti, 2006, Komesvarakul et al., 2006, Lawrence \& Rees. 2000, Vandamme, 2002, Yuan et al., 2008, as cited in Nguyen et al., 2010). Xie et al., 2005 demonstrated that rhamnolipids could be successfully used to form microemulsions using medium chain alcohols as cosurfactant. Subsequently, the same Authors observed that the phase behavior and microstructure of these microemulsions were rational to the conformational changes of rhamnolipid molecules at the interface of oil/water (Xie et al., 2007). Microemulsion technique using oil-water-surfactant mixture has also emerged as a promising method for nanoparticle synthesis and can be used to synthesize different types of particles (Eastoe et al., 2006, as cited in Palanisamy \& Raichur, 2009). Palanisamy \& Raichur, (2009), for example, successfully used rhamnolipids as the surfactant to synthesize spherical nickel oxide nanoparticles by microemulsion technique. In another work, Nguyen \& Sabatini, (2009) were able to formulate alcohol-free microemulsions using rhamnolipid biosurfactant and rhamnolipid mixtures.

Lecithin-based microemulsions have proven to be desirable in biocompatible formulations due to their tendency to mimic the phospholipid nature of cell membranes (Nguyen et al., 2010). In a recent report Nguyen et al., (2010) formulated and evaluated microemulsions of lecithin/rhamnolipid/sophorolipid biosurfactants with a range of oils. Sophorolipid played an important role as the hydrophobic component in these formulations and the phase behavior of these biocompatible microemulsions did not change significantly with changing temperature and electrolyte concentration, making them desirable for cosmetic and drug delivery applications.

\subsection{A survey over biotechnological commercial applications and patents of biosurfactants and bioemulsifiers}

Due to their broad-range of functional properties and the diverse synthetic capabilities of microbes, biological surfactants and emulsifiers have been recently used in various industries like detergents and soaps, petroleum, textile, agriculture, cosmetic, medicine and food (Banat et al., 2000, 2010). Due to their environmental acceptability, biodegradability and lower toxicity, they are generally accepted as good candidates to substitute synthetic surfactants. Commercial applications of biosurfactants and bioemulsifiers in the biotechnological field are mainly related to the oil industry, enhanced oil recovery and bioremediation technologies (Desai \& Banat, 1997). However, interesting marketable products and patents have been issued in the last few years in the health care and cosmetic industries, reviewed by Shete et al., (2006) and Banat et al., (2010).

Sugar-based biosurfactants, sophorolipids in particular, are very attractive in these fields, because of their good detergency, emulsifying, foaming and dispersing properties (Faivre \& Rosilio, 2010). Sophorolipids are better solubilizers than emulsifiers, but their derivatives 
containing propylene glycol have excellent hygroscopic properties and are applied as moisturizer or softener in cosmetic products (Faivre \& Rosilio, 2010). For example, a product containing $1 \mathrm{~mol}$ of sophorolipid and $12 \mathrm{~mol}$ of propylene glycol has excellent skin compatibility and is used commercially as a skin moisturizer (Yamane, 1987, as cited in Desai \& Banat 1997). Sophorolipid is commercially used by Kao Co. Ltd. as a humectant for cosmetic makeup brands such as Sofina. This company has developed a fermentation process for sophorolipid production, and after a two-step esterification process, the product finds application in lipstick and as moisturizer for skin and hair products (Inoue et al., 1979 a, 1979b, as cited in Desai \& Banat, 1997). Moreover, sophorolipids are also believed to stimulate the leptin synthesis through adipocytes, in this way reducing the subcutaneous fat overload (Pellecier \& André, 2004, as cited in Van Bogaert \& Soetaert, 2010).

The French company Soliance (http://www.groupesoliance.com) produces sophorolipidbased cosmetics for the body and skin and the Korean MG Intobio Co. commercializes Sopholine cosmetics (Van Bogaert \& Soetaert, 2010). They are also found in cleaning soap mixtures (Ecover ${ }^{\mathrm{TM}}$ products). Despite the high number of scientific publications and patents, industrial surfactin applications still remain quite limited (Jacques, 2010). Sold by SIGMA and SHOWA DENKO for analytical or laboratory purposes, the compound is also available in several Japanese cosmetic products.

During the last decades, many patents have been issued worldwide in relation with applications of biosurfactants and bioemulsifiers in the health care field (Shete et al., 2006). Bioemulsifiers produced by Acinetobacter calcoaceticus, for examples, have been used in shampoos and soaps against acne and eczema and in personal care products. The skin cleansing cream and lotion containing these bioemulsifiers have, among other properties, the ability to interfere with microbial adhesion on skin or hair (Hayes et al., 1989, 1990, 1991, 1992, as cited in Shete et al., 2006). Viscosin and analogues have been patented as antibacterial, antiviral, antitrypanosomal therapeutic compounds that inhibit the growth of Mycobacterium tuberculosis, Herpes simplex virus 2 and/or Trypanosoma cruzi (Burke et al., 1999, as cited in Shete et al., 2006). Lactobacillus biosurfactants have also been patented as inhibitors of adherence and colonization of bacterial pathogens on medical devices (Reid et al., 2000).

Another interesting patented area is related to antimicrobial biosurfactant peptides produced by probiotic strains able to selectively bind to collagen and inhibit infections around wounds at the site of implants and biofilms associated with infections in mammals (Howard et al., 2002, as cited in Shete et al., 2006). Sophorolipids, in particular have been the object of many patents as moisturizing agents and for the amelioration of skin physiology, skin restructuration and repair (Shete et al., 2006). Sophorolipids are also used for the treatment of skin, as an activator of macrophages, and as agent in fibrinolytic healing, desquamating and depigmenting process (Maingault, 1999 as cited in Shete et al., 2006). A germicidal composition containing fruit acids, a surfactant and a sophorolipid biosurfactant, able to kill in 30 seconds $100 \%$ of E. coli, Salmonella and Shigella, has been patented for cleaning fruits, vegetable, skin and hair (Pierce \& Heilman, 2001).

Rhamnolipids in comparison have been patented in a process to make some liposomes and emulsions (Ishigami \& Suzuki 1997; Ramisse et al., 2000) both important in the cosmetic industry. More recently an activator and anti-aging agent containing MEL as active ingredient has been patented (Suzuki et al., 2010). Another recent invention is directed to polymeric acylated biosurfactants that can self-assemble or auto-aggregate into polymeric micellar structures useful in topically-applied dermatologic products (Owen \& Fan, 2010). 
Another patent has been deposited about a biosurfactant composition produced by a new $B$. licheniformis strain, with anti-adhesion activity against biofilm producer microbial pathogens (Martinotti et al., 2009).

\section{Conclusions and perspectives}

As evidenced by the growing number of publications on the topic of biosurfactants, there is an increasing interest in the study of these molecules and their potential applications. The demand for new specialty surfactants in the agriculture, cosmetic, food, pharmaceutical, and environmental industries is steadily increasing and biosurfactants, as effective and environmentally compatible compounds, perfectly meet this demand (Banat et al., 2000, 2010; Mukherjee et al., 2006).

The most important limitation for the commercial use of biosurfactants is the complexity and high cost of production, which has limited the development of their use on a large scale (Soberón-Chávez \& Maier, 2010). However, the proven antimicrobial, anti-adhesive, immune-modulating properties of biosurfactants and the recent successful applications in gene therapy, immunotherapy and medical insertion safety suggest that it is worth persisting in this field. Moreover, in pharmaceutical and biomedical sectors, the high cost of production could be compensated for by the small amounts of product required. In fact, it has been elucidated that biosurfactants used as pharmaceutical agents are needed only in very low concentrations (Cameotra \& Makkar, 2004). Prerequisites for making biosurfactant production more profitable and economically feasible include optimized growth/production conditions and novel and efficient multi-step downstream processing methods as well as the use of recombinant varieties of microorganisms or selected hyperproducing mutants, which can grow on a wide range of cheap renewable substrates (Muthusamy et al., 2008).

Recent advances in the area of biomedical application are probably going to take the lead due to higher potential economic returns. Moreover, due to their self-assembly properties, new and fascinating applications in nanotechnology are predicted for biosurfactants (Kitamoto et al., 2009; Palanisamy, 2008; Reddy et al., 2009). In-depth studies of their natural roles in microbial competitive interactions, cell-to-cell communication, pathogenesis, motility and biofilm formation and maintenance could suggest improved and interesting future applications.

\section{Acknowledgements}

This work was partially supported by the Local Research funding of the Italian Ministero dell'Istruzione, dell'Università e della Ricerca.

\section{References}

Abalos A, Pinazo A, Infante MR, Casals M, García F \& Manresa A (2001) Physicochemical and antimicrobial properties of new rhamnolipids produced by Pseudomonas aeruginosa AT10 from soybean oil refinery wastes. Langmuir. 17:1367-1371

Arima K, Kakinuma A \& Tamura G (1968) Surfactin, a crystalline peptide-lipid surfactant produced by Bacillus subtilis: isolation, characterization and its inhibition of fibrin clot formation. Biochem Biophys Res Commun. 31:488-494 
Arutchelvi J \& Doble M (2010) Mannosylerythritol lipids: microbial production and their applications, In: Biosurfactants: From Genes to Applications, Soberón-Chávez G Ed., pp. 145-177, Springer, Münster, Germany

Arutchelvi JI, Bhaduri S, Uppara PV \& Doble M (2008) Mannosylerythritol lipids: a review. J Ind Microbiol Biotechnol. 35:1559-1570

Banat IM (1995a) Biosurfactants production and use in microbial enhanced oil recovery and pollution remediation: A review. Bioresource Technol. 51:1-12

Banat IM (1995b) Biosurfactants characterization and use in pollution removal; state of the art. A review. ACTA Biotechnologica. 15:251-26

Banat IM, Franzetti A, Gandolfi I, Bestetti G, Martinotti MG, Fracchia L, Smyth TJ \& Marchant R (2010) Microbial biosurfactants production, applications and future potential. Appl Microbiol Biotechnol. 87:427-44.

Banat IM, Makkar RS \& Cameotra SS (2000) Potential commercial applications of microbial surfactants. Appl Microbiol Biotechnol. 53:495-508

Barrons R \& Tassone D (2008) Use of Lactobacillus probiotics for bacterial genitourinary infections in women: a review. Clin Ther. 30:453-468

Basak P, Adhikari B, Banerjee I \& Maiti TK (2009) Sustained release of antibiotic from polyurethane coated implant materials. J Mater Sci Mater Med. 20:S213-S221

Becher P (Ed.) (1965) Emulsions, Theory and practice, Reinhold Publishing, New York, USA.

Benincasa M, Abalos A, Oliveira I \& Manresa A (2004) Chemical structure, surface properties and biological activities of the biosurfactant produced by Pseudomonas aeruginosa LBI from soapstock. Anton Leeuw Int J G. 85:1-8

Bernheimer AW \& Avigad LS (1970) Nature and properties of a cytolytic agent produced by Bacillus subtilis. J Gen Microbiol. 6:361-366

Besson, F, Peypoux F, Michel G, \& Delcambe L (1978). Identification of antibiotics of iturin group in various strains of Bacillus subtilis. J. Antibiot. (Tokyo) 31:284-288

Besson $\mathrm{F}$ et al. (1976) Characterisation of iturin A in antibiotics from various strains of Bacillus subtilis. J. Antibiot 29: 1043-1049

Biria D, Maghsoudi E, Roostaazad R, Dadafarin H, Lotfi AS \& Amoozegar MA (2010) Purification and characterization of a novel biosurfactant produced by Bacillus licheniformis MS3. World J Microbiol Biotechnol. 26:871-878

Bodour AA, Miller-Maier RM (1998) Application of a modified drop-collapse technique for surfactant quantitation and screening of biosurfactant-producing microorganisms. J. Microbiol Methods. 32:273-280

Boisselier E \& Astruc D (2009) Gold nanoparticles in nanomedicine: preparations, imaging, diagnostics, therapies and toxicity. Chem Soc Rev. 38:1759-1782

Bonmatin JM, Laprevote O \& Peypoux F (2003) Diversity among microbial cyclic lipopeptides: iturins and surfactins. Activity-structure relationships to design new bioactive agents. Comb Chem High Throughput Screen. 6:541-556

Bouffioux O, Berquand A, Eeman M, Paquot M, Dufrêne YF, Brasseur R \& Deleu M (2007) Molecular organization of surfactin-phospholipid monolayers: effect of phospholipid chain length and polar head. Biochim Biophys Acta Biomembr. 1768:1758-1768

Brasseur R, Braun N, El Kirat K, Deleu M, Mingeot-Leclercq MP \& Dufrêne YF (2007) The biologically important surfactin lipopeptide induces nanoripples in supported lipid bilayers. Langmuir 23:9769-9772 
Buijssen KJ, Harmsen HJ, van der Mei HC, Busscher HJ \& van der Laan BF (2007) Lactobacilli: important in biofilm formation on voice prostheses. Otolaryngol Head Neck Surg. 137:505-507

Busscher HJ, Bruinsma G, van Weissenbruch R, et al. (1998) The effect of buttermilk consumption on biofilm formation on silicone rubber voice prostheses in an artificial throat. Eur Arch Otorhinolaryngol. 255:410-413

Busscher HJ, van Hoogmoed CG, Geertsema-Doornbusch GI, van der Kuijl-Booij M \& van der Mei HC. (1997) Streptococcus thermophilus and its biosurfactants inhibit adhesion by Candida spp. on silicone rubber. Appl Environ Microbiol. 63:3810-3817.

Byeon SE, Lee YG, Kim BH, Shen T, Lee SY, Park HJ, Park SC, Rhee MH \& Cho JY (2008) Surfactin blocks NO production in lipopolysaccharide-activated macrophages by inhibiting NF-kB activation. J Microbiol Biotechnol. 18:1984-1989

Çaglar E, Kargul B \& Tanboga I (2005) Bacteriotherapy and probiotics role on oral health. Oral Dis. 11:131-137

Cameotra SS \& Makkar RS (2004) Recent applications of biosurfactants as biological and immunological molecules. Curr Opin Microbiol. 7:262-266

Cao XH, Wang AH, Wang CL, Mao DZ, Lu MF, Cui YQ \& Jiao RZ (2010) Surfactin induces apoptosis in human breast cancer MCF- 7 cells through a ROS/JNK-mediated mitochondrial/caspase pathway. Chem Biol Interact 183:357-362

Cao XH, Zhao SS, Liu DY, Wang Z, Niu LL, Hou LH \& Wang CL (2011) ROS-Ca(2+) is associated with mitochondria permeability transition pore involved in surfactininduced MCF-7 cells apoptosis. Chem Biol Interact. 190(1):16-27

Carrillo C, Teruel JA, Aranda FA \& Ortiz A (2003) Molecular mechanism of membrane permeabilization by the peptide antibiotic surfactin. Biochem Biophys Acta. 1611: 9197

Chassot F, Negri MF, Svidzinski AE, Donatti L, Peralta RM, Svidzinski TI \& Consolaro ME (2008) Can intrauterine contraceptive devices be a Candida albicans reservoir? Contraception. 77:355-359

Chen J, Song X, Zhang H, Qu Y \& Miao J (2006) Sophorolipid produced from the new yeast strain Wickerhamiella domercqiae induces apoptosis in H7402 human liver cancer cells. Appl Microbiol Biotechnol. 72:52-59

Chen ML, Penfold J, Thomas RK, Smyth TJP, Perfumo A, Marchant R, Banat IM, Stevenson P, Parry A, Tucker I \& Grillo I (2010a) Solution self-assembly and adsorption at the air-water interface of the mono and di-rhamnose rhamnolipids and their mixtures. Langmuir. 26:18281-18292

Chen ML, Penfold J, Thomas RK, Smyth TJP, Perfumo A, Marchant R, Banat IM, Stevenson P, Parry A, Tucker I, \& Grillo I (2010b) Mixing behaviour of the biosurfactant, rhamnolipid, with a conventional anionic surfactant, sodium dodecyl benzene sulfonate. Langmuir. 26:17958-17968

Chung YR, Kim CH, Hwang I \& Chun J (2000) Paenibacillus koreensis sp. nov. A new species that produces an iturin-like antifungal compound. Int J Syst Evol Microbiol. 50:14951500

Cirigliano, MC \& Carman, GM, (1985) Purification and characterization of liposan, a bioemulsifier from Candida lipolytica. Appl Environ Microbiol. 50:846-850 
Cosson P, Zulianello L, Join-Lambert O, Faurisson F, Gebbie L, Benghezal M, van Delden C, Curty LK \& Köhler T (2002) Pseudomonas aeruginosa virulence analyzed in a Dictyostelium discoideum host system. J Bacteriol. 184(11):3027-3033

Cribby S, Taylor M \& Reid G (2008) Vaginal microbiota and the use of probiotics. Interdisciplinary perspectives on infectious diseases. Article ID 256490, 9 pages.

Das P, Mukherjee S \& Sen R (2008) Antimicrobial potential of a lipopeptide biosurfactant derived from a marine Bacillus circulans. J Appl Microbiol. 104:1675-1684

Dastgheib SMM, Amoozegar MA, Elahi E, Asad S \& Banat IM (2008) Bioemulsifier production by a halothermophilic Bacillus strain with potential applications in microbially enhanced oil recovery. Biotechnol Lett. 30(2):263-270

Deleu M, Paquot M \& Nylander T (2008) Effect of fengycin, a lipopeptide produced by Bacillus subtilis, on model biomembranes. Biophys J. 94:2667-2679

Dempsey KE, Riggio MP, Lennon A, Hannah VE, Ramage G, Allan D \& Bagg J (2007) Identification of bacteria on the surface of clinically infected and noninfected prosthetic hip joints removed during revision arthroplasties by $16 \mathrm{~S}$ rRNA gene sequencing and by microbiological culture. Arthritis Res Ther. 9:R46

Desai JD \& Banat IM (1997) Microbial production of surfactants and their commercial potential. Microbiol Mol Biol Rev. 61:47-64

Donadio S, Monciardini P, Alduina R, Mazza P, Chiocchini C, Cavaletti L, Sosio M \& Puglia AM (2002) Microbial technologies for the discovery of novel bioactive metabolite. J Biotechnol. 99:187-198

Donlan RM \& Costerton JW (2002) Biofilms: survival mechanisms of clinically relevant microorganisms. Clin Microbiol Rev. 15: 167-193

Eeman M, Francius G, Dufrêne YF, Nott K, Paquot M \& Deleu M (2009) Effect of cholesterol and fatty acids on the molecular interactions of fengycin with stratum corneum mimicking lipid monolayers. Langmuir. 25:3029-3039

Faivre V \& Rosilio V (2010) Interest of glycolipids in drug delivery: from physicochemical properties to drug targeting Expert Opin Drug Deliv. 7(9):1031-1048

Falagas ME, Betsi GE, Tokas T \& Athanassiou S (2006a) Probiotics for prevention of recurrent urinary tract infections in women: a review of the evidence from microbiological and clinical studies. Drugs. 66:1253-1261.

Falagas ME, Betsi GI \& Athanasiou S (2007) Probiotics for the treatment of women with bacterial vaginosis. Clin Microbiol Infect. 13: 657-664

Falagas ME, Betsi GI, Athanasiou S (2006b) Probiotics for prevention of recurrent vulvovaginal candidiasis: a review. Antimicrob Chemother. 58:266-272.

Falagas ME \& Makris GC (2009) Probiotic bacteria and biosurfactants for nosocomial infection control: a hypothesis. J Hosp Infect. 71(4):301-306

Fassi FL, Wroblewski H \& Blanchard A (2007) Activities of antimicrobial peptides and synergy with enrofloxacin against Mycoplasma pulmonis. Antimicrob Agents Chemother. 51:468-74

Federle MJ \& Bassler BL (2003) Interspecies communication in bacteria. J Clin Invest. 112:1291-1299

Fracchia L, Cavallo M, Allegrone G \& Martinotti MG (2010) A Lactobacillus-derived biosurfactant inhibits biofilm formation of human pathogenic Candida albicans biofilm producers, In: Current Research, Technology and Education Topics in Applied 
Microbiology and Microbial Biotechnology (vol. 2), Mendez Vilas A Ed., pp. 827-837, FORMATEX, Spain

Francius G, Dufour S, Deleu M, Paquot M, Mingeot-Leclercq MP \& Dufrêne YF (2008) Nanoscale membrane activity of surfactins: influence of geometry, charge and hydrophobicity. Biochim Biophys Acta. 1778:2058-2068

Franzetti A, Tamburini E \& Banat IM (2010a) Applications of biological surface active compounds in remediation technologies, In: Biosurfactants, BIOSURFACTANTS Book Series: Advances in Experimental Medicine and Biology, Sen R Ed., Volume: 672, pp. 121-134, Landes Bioscience, Austin, TX

Franzetti A, Gandolfi I, Bestetti G, Smyth TJP \& Banat IM (2010b) Production and applications of trehalose lipid biosurfactants. Eur J Lipid Sci Technol. 112:617-627

Gautam KK \& Tiagi VK (2006) Microbial surfactants: A review. J Oleo Sci. 55:155-166

Grangemard I, Wallach J, Maget-Dana R \& Peypoux F (2001) Lichenysin: a more efficient cation chelator than surfactin. Appl Biochem Biotechnol. 90:199-210

Gudiña EJ, Teixeira JA \& Rodrigues LR (2010) Isolation and functional characterization of a biosurfactant produced by Lactobacillus paracasei. Colloids Surf B Biointerfaces. 76:298304

Gupta V \& Garg R (2009) Probiotics. Indian J Med Microbiol. 27:202-209

Hall-Stoodley L, Costerton JW \& Stoodley P (2004) Bacterial biofilms: from the natural environment to infectious diseases. Nat Rev Microbiol. 2:95-108

Han Y, Huang X, Cao M \& Wang Y (2008) Micellization of surfactin and its effect on the aggregate conformation of amyloid $\beta(1-40)$. J Phys Chem B. 112:15195-15201

Hancock, REW \& Chapelle DS (1999) Pepedide antibiotics. Antimicrob Agents Chemother. 43:1317-1323

Hatakka K, Ahola AJ, Yli-Knuuttila H, Richardson M, Poussa T \& Meurman JK (2007) Probiotics reduce the prevalence of oral Candida in the elderly-a randomized controlled trial. J Dent Res. 86:125-130

Hong HA, Duc LH \& Cutting SM (2005) The use of bacterial spore formers as probiotics. FEMS Microbiol Rev. 29:813-835

Horowitz S, Gilbert JN \& Griffin WM (1990) Isolation and characterization of a surfactant produced by Bacillus licheniformis 86. J Ind Microbiol Biot. 6(4):243-248

Huang X, Lu Z, Bie X, Lü F, Zhao H \& Yang S (2007) Optimization of inactivation of endospores of Bacillus cereus by antimicrobial lipopeptides from Bacillus subtilis fmbj strains using a response surface method. Appl Microbiol Biotechnol. 74:454-461

Huang X, Lu Z, Zhao H, Bie X, Lü FX \& Yang S (2006) Antiviral activity of antimicrobial lipopeptide from Bacillus subtilis fmbj against pseudorabies virus, porcine parvovirus, newcastle disease virus and infectious bursal disease virus in vitro. Int J Pept Res Ther. 12:373-377

Huang X, Suo J \& Cui Y (2011) Optimization of antimicrobial activity of surfactin and polylysine against Salmonella enteritidis in milk evaluated by a response surface methodology. Foodborne Pathog Dis. 8(3):439-43

Igarashi S, Hattori Y \& Maitani Y (2006) Biosurfactant MEL-A enhances cellular association and gene transfection by cationic liposome. J Control Release. 112:362-368

Imamura Y, Chandra J, Mukherjee PK, Lattif AA, Szczotka-Flynn LB, Pearlman E, Lass JH, O'Donnell K \& Ghannoum MA (2008) Fusarium and Candida albicans biofilms on 
soft contact lenses: model development, influence of lens type, and susceptibility to lens care solutions. Antimicrob Agents Chemother. 52: 171-182

Imura T, Ito S, Azumi R, Yanagishita H, Sakai H, Abe M \& Kitamoto D (2007) Monolayers assembled from a glycolipid biosurfactant from Pseudozyma (Candida) antarctica serve as a high-affinity ligand system for immunoglobulin G and M. Biotechnol Lett. 29:865-870

Imura T, Masuda Y, Ito S, Worakitkanchanakul W, Morita T, Fukuoka T, Sakai H, Abe M \& Kitamoto D (2008) Packing density of glycolipid biosurfactant monolayers give a significant effect on their binding affinity toward immunoglobulin G. J Oleo Sci. 57:415-22

Inoh Y, Furuno T, Hirashima N \& Nakanishi M (2009) Nonviral vectors with a biosurfactant MEL-A promote gene transfection into solid tumors in the mouse abdominal cavity. Biol Pharm Bull. 32:126-128

Inoh Y, Furuno T, Hirashima N, Kitamoto D \& Nakanishi M (2010) The ratio of unsaturated fatty acids in biosurfactants affects the efficiency of gene transfection. Int $J$ Pharmaceut. 398:225-230

Inoh Y, Kitamoto D, Hirashima N \& Nakanishi M (2001) Biosurfactants of MEL-A increase gene transfection mediated by cationic liposomes. Biochem Biophys Res Commun. 289:57-61

Inoh Y, Kitamoto D, Hirashima N \& Nakanishi M (2004) Biosurfactant MEL-A dramatically increases gene transfection via membrane fusion. J Control Release 94:423-431.

Ishigami Y \& Suzuki S (1997) Development of biochemicals-functionalization of biosurfactants and natural dyes. Prog Org Coatings. 31:51-61.

Ito S, Imura T, Fukuoka T, Morita T, Sakai H, Abea M \& Kitamoto D (2007) Kinetic studies on the interactions between glycolipid biosurfactant assembled monolayers and various classes of immunoglobulins using surface plasmon resonance. Colloids Surf B Biointerfaces. 58:165-171

Jaques P (2010) Surfactin and other lipopeptides from Bacillus spp. In: Biosurfactants: From Genes to Applications, Soberón-Chávez G Ed., pp. 57-91, Springer, Münster, Germany

Jung M, Lee S \& Kim H (2000) Recent studies on natural products as anti-HIV agents. Curr Med Chem. 7:649-661

Kalishwaralal K, Deepak V, Pandiana SBRK, Kottaisamy M, BarathManiKanth S, Kartikeyan B \& Gurunathan S (2010) Biosynthesis of silver and gold nanoparticles using Brevibacterium casei. Colloids Surf B Biointerfaces. 77:257-262

Kalmokoff ML, Austin JW, Wan XD, Sanders G, Banerjee S \& Farber JM (2001) Adsoption, attachment and biofilm formation among isolates of Listeria monocytogenes using model conditions. J Appl Microbiol. 91:725-734

Kim BS, Lee JY \& Hwang BK (2000) In vivo control and in vitro antifungal activity of rhamnolipid B, a glycolipid antibiotic, against Phytophthora capsici and Colletotrichum orbiculare. Pest Manag Sci. 56:1029-1035

Kim H, Ryu JH \& Beuchat LR (2006) Attachment of and biofilm formation by Enterobacter sakazakii on stainless steel and enteral feeding tubes. Appl Environ Microbiol. 72:5846-5856

Kim K, Yoo D, Kim Y, Lee B, Shin D \& Kim E-K (2002) Characteristics sophorolipid as an antimicrobial agent. J Microbiol Biotechnol. 12:235-241 
Kim PI, Ryu J, Kim YH \& Chi YT (2010) Production of biosurfactant lipopeptides iturin A, fengycin, and surfactin A from Bacillus subtilis CMB32 for control of Colletotrichum gloeosporioides. J Microbiol Biotechnol. 20(1):138-145

Kiran GS, Sabarathnam B \& Selvin J (2010a) Biofilm disruption potential of a glycolipid biosurfactant from marine Brevibacterium casei. FEMS Immunol Med Microbiol. 59:432-438

Kiran GS, Sabu A \& Selvin J (2010b) Synthesis of silver nanoparticles by glycolipid biosurfactant produced from marine Brevibacterium casei MSA19. J Biotechnol. 148:221-225

Kitamoto D, Isoda H, Nakahara T. (2002) Functions and potential applications of glycolipid biosurfactants-from energy-saving materials to gene delivery carriers. J Biosci Bioeng. 94(3):187-201.

Kitamoto D, Morita T, Fukuoka T, Konishi M \& Imura T (2009) Self-assembling properties of glycolipid biosurfactants and their potential applications. Curr Opin Colloid Interface Sci. 14:315- 328

Kitamoto D, Toma K \& Hato M (2005) Glycolipid-based nanomaterials, In: Handbook of Nanostructured Biomaterials and Their Applications in Nanobiotechnology, vol. 1, Nalwa HS Ed., p. 239-271, American Science Publishers, California, USA

Kitamoto D, Yanagishita H, Shinbo T, Nakane T, Kamisawa C \& Nakahara T (1993) Surface active properties and antimicrobial activities of mannosylerythritol lipids as biosurfactants produced by Candida antarctica. J Biotechnol. 29:91-96

Kõll P, Mändar R, Marcotte H, Leibur E, Mikelsaar M \& Hammarström L (2008) Characterization of oral lactobacilli as potential probiotics for oral health. Oral Microbiol Immunol. 23:139-147

Konishi M, Imura T, Fukuoka T, Morita T \& Kitamoto D (2007) A yeast glycolipid biosurfactant, mannosylerythritol lipid, shows high binding affinity towards lectins on a self-assembled monolayer system. Biotechnol Lett. 29:473-480

Kumar A, Ali A \& Yerneni LK (2007) Effectiveness of a mycoplasma elimination reagent on a mycoplasma-contaminated hybridoma cell line. Hybridoma (Larchmt). 26(2):104106

Kumar CG, Mamidyala SK, Das B, Sridhar B, Devi GS \& Karuna MS (2010) Synthesis of biosurfactant-based silver nanoparticles with purified rhamnolipids isolated from Pseudomonas aeruginosa BS-161R. J Microbiol Biotechnol. 20:1061-1068

Kuyukina MS, Ivshina IB, Gein SV, Baeva TA \& Chereshnev VA (2007) In vitro immunomodulating activity of biosurfactant glycolipid complex from Rhodococcus ruber. Bull Exp Biol Med.144:326-30.

Landman D, Georgescu C, Martin DA \& Quale J (2008) Polymyxins revisited. Clin Microbiol Rev. 21:449-465

Lang S (2002) Biological amphiphiles (microbial biosurfactants). Curr Opin Coll Int Sci. 7:1220

Lang S \& Philp JC (1998) Surface-active lipids in Rhodococci. Anton Leeuw Int. J G. 74:59-70.

Lin SC (1996) Biosurfactants: recent advances. J Chem Tech Biotechnol. 66:109-120

Litzler PY, Benard L, Barbier-Frebourg N, Vilain S, Jouenne T, Beucher E, Bunel C, Lemeland JF \& Bessou JP (2007) Biofilm formation on pyrolytic carbon heart valves: influence of surface free energy, roughness, and bacterial species. J Thorac Cardiovasc Surg. 134:1025-1032 
Lu JR, Zhao XB \& Yaseen M (2007) Biomimetic amphiphiles: biosurfactants. Curr Opin Colloid Interface Sci. 12:60-67

Luna JM, Rufino RD, Sarubbo LA, Rodrigues LR, Teixeira JA \& de Campos-Takaki GM (2011) Evaluation antimicrobial and antiadhesive properties of the biosurfactant lunasan produced by Candida sphaerica UCP 0995. Curr Microbiol. 62:1527-1534

Maier RM (2003) Biosurfactants: evolution and diversity in bacteria. Adv Appl Microbiol. 52: 101-121

Maitani Y, Yano S, Hattori Y, Furuhata M \& Hayashi K (2006) Liposome vector containing biosurfactant-complexed DNA as herpes simplex virus thymidine kinase gene delivery system. J Liposome Res. 16:359-72.

Martinotti MG, Rivardo F Allegrone G, Ceri H, Turner R (2009) Biosurfactant composition produced by a new Bacillus licheniformis strain, uses and products thereof. International patent PCT/IB2009/055334, 25 November

Matsuyama T, Tanikawa T, \& Nakagawa Y (2010) Serrawettins and other surfactants produced by Serratia. In: Biosurfactants: From Genes to Applications, Soberón-Chávez G Ed., pp. 93-120, Springer, Münster, Germany

McInerney MJ, Javaheri M \& Nagle DP (1990) Properties of the biosurfactant produced by Bacillus liqueniformis strain JF-2. I. J. Microbiol Biotechnol. 5:95-102

Merk K, Borelli C \& Korting HC (2005) Lactobacilli-bacteria-host interactions with special regard to the urogenital tract. Int J Med Microbiol. 295:9-18

Meurman JH (2005) Probiotics: do they have a role in oral medicine and dentistry? Eur J Oral Sci. 113:188-196

Meurman JH \& Stamatova I (2007) Probiotics: contributions to oral health. Oral Dis. 13:443445

Meylheuc T, Methivier C, Renault M, Herry JM, Pradier CM \& Bellon-Fontaine MN (2006a) Adsorption on stainless steel surfaces of biosurfactants produced by gram-negative and gram-positive bacteria: consequence on the bioadhesive behavior of Listeria monocytogenes. Colloids Surf B Biointerfaces.52:128-137

Meylheuc T, Renault M \& Bellon-Fontaine MN (2006b) Adsorption of a biosurfactant on surfaces to enhance the disinfection of surfaces contaminated with Listeria monocytogenes. Int J Food Microbiol. 109:71-78

Mimee B, Labbé C, Pelletier R \& Bélanger RR (2005) Antifungal activity of flocculosin, a novel glycolipid isolated from Pseudozyma flocculosa. Antimicrob Agents Chemother. 49:1597-1599

Mimee B, Pelletier R \& Bélanger RR (2009) In vitro antibacterial activity and antifungal mode of action of flocculosin, a membrane-active cellobiose lipid. J Appl Microbiol. 107:989-996

Mireles JR II, Toguchi A \& Harshey RM (2001) Salmonella enterica serovar typhimurium swarming mutants with altered biofilm forming abilities: surfactin inhibits biofilm formation. J Bacteriol. 183:5848-5854

Mohammad Abdel-Mawgoud A, Hausmann R, Lépine F, Müller MM \& Déziel E (2010) Rhamnolipids: detection, analysis, biosynthesis, genetic regulation, and bioengineering of production, In: Biosurfactants: From Genes to Applications, SoberónChávez G Ed., pp. 13-55, Springer, Münster, Germany

Morikawa M (2006) Beneficial biofilm formation by industrial bacteria Bacillus subtilis and related species. J Biosci Bioeng. 101:1-8 
Morikawa M, Hirata Y, Imanaka T (2000). A study on the structure-function relationship of the lipopeptide biosurfactants. Biochim Biophys Acta. 1488:211-218

Morikawa M, Ito M \& Imanaka T (1992) Isolation of a new surfactin producer Bacillus pumilus A-1, and cloning and nucleotide sequence of the regulator gene, psf-1. J Ferment Bioeng. 74:255-261

Morita T, Fukuoka T, Konishi M, Imura T, Yamamoto S, Kitagawa M, Sogabe A \& Kitamoto D (2009a) Production of a novel glycolipid biosurfactant, mannosylmannitol lipid, by Pseudozyma parantarctica and its interfacial properties. Appl Microbiol Biotechnol. 83:1017-1025

Morita T, Kitagawa M, Suzuki M, Yamamoto S, Sogabe A, Yanagidani S, Imura T, Fukuoka T \& Kitamoto D (2009b) A yeast glycolipid biosurfactant, mannosylerythritol lipid, shows potential moisturizing activity toward cultured human skin cells: the recovery effect of MEL-A on the SDS-damaged human skin cells. J Oleo Sci. 58:639642

Morita T, Kitagawa M, Yamamoto S, Suzuki M, Sogabe A, Imura T, Fukuoka T \& Kitamoto D (2010) Activation of fibroblast and papilla cells by glycolipid biosurfactants, mannosylerythritol lipids. J Oleo Sci. 59:451-5

Mukherjee S, Das P \& Sen R (2006) Towards commercial production of microbial surfactants. Trends Biotechnol. 24:509-515

Muthusamy K, Gopalakrishnan S, Ravi TK \& Sivachidambaram P (2008) Biosurfactants: Properties, commercial production and application. Curr Sci. 94:736-747

Nakanishi M, Inoh Y, Kitamoto D \& Furuno T (2009) Nano vectors with a biosurfactant for gene transfection and drug delivery. J Drug Delivery Sci Technol. 19:165-169.

Narayanan J, Ramji R, Sahu H \& Gautam P (2010) Synthesis, stabilisation and characterisation of rhamnolipid-capped ZnS nanoparticles in aqueous medium. IET Nanobiotechnol. 4:29-34.

Narayanan KB \& Sakthivel N (2010) Biological synthesis of metal nanoparticles by microbes. Adv Colloid Interfac. 156:1-13

Naruse N, Tenmyo O, Kobaru S, Kamei H, Miyaki T, Konishi M \& Oki T (1990) Pumilacidin, a complex of new antiviral antibiotics: production, isolation, chemical properties, structure and biological activity. J Antibiot. (Tokyo) 43:267-280

Neu TR (1996) Significance of bacterial surface-active compounds in interaction of bacteria with interfaces. Microbiol Rev. 60:151-166

Nguyen TT \& Sabatini DA (2009) Formulating alcohol-free microemulsions using rhamnolipid biosurfactant and rhamnolipid mixtures. J Surfact Deterg. 12:109-115

Nguyen TTL, Edelen A, Neighbors B \& Sabatini DA (2010) Biocompatible lecithin-based microemulsions with rhamnolipid and sophorolipid biosurfactants: formulation and potential applications. J Colloid Interface Sci. 348:498-504

Nicoli S, Eeman M, Deleu M, Bresciani E, Padula C \& Santi, P (2010) Effect of lipopeptides and iontophoresis on aciclovir skin delivery. J Pharm Pharmacol. 62:702-708

Nithya C \& Pandian SK (2010) The in vitro antibiofilm activity of selected marine bacterial culture supernatants against Vibrio spp. Arch Microbiol. 192:843-854

Nitschke M, Araújo LV, Costa SG, Pires RC, Zeraik AE, Fernandes AC, Freire DM \& Contiero J (2009) Surfactin reduces the adhesion of food-borne pathogenic bacteria to solid surfaces. Lett Appl Microbiol. 49:241-247 
Nitschke M, Costa SG \& Contiero J (2010) Structure and applications of a rhamnolipid surfactant produced in soybean oil waste. Appl Biochem Biotechnol. 160(7):2066-74

Ortiz A, Teruel JA, Espuny MJ, Marqués A, Manresa Á \& Aranda FJ (2008) Interactions of a Rhodococcus sp. biosurfactant trehalose lipid with phosphatidylethanolamine membranes. Biochim Biophys Acta. 1778:2806-2813

Ortiz A, Teruel JA, Espuny MJ, Marqués A, Manresa Á \& Aranda FJ (2009) Interactions of a bacterial biosurfactant trehalose lipid with phosphatidylserine membranes. Chem Phys Lipids. 158:46-53

Osada, H (1998) Bioprobe for investigating mammlian cell cycles control. J. Antibiotics 51:973-982

Owen D \& Fan L (2010) Polymeric Biosufactants. US Patent 20100144643, 6 October

Palanisamy P (2008) Biosurfactant mediated synthesis of NiO nanorods. Mat Lett. 62:743-746

Palanisamy P \& Raichur AM (2009) Synthesis of spherical NiO nanoparticles through a novel biosurfactant mediated emulsion technique. Mater Scie Eng C. 29:199-204

Park SY \& Kim Y (2009) Surfactin inhibits immunostimulatory function of macrophages through blocking NK-кB, MAPK and Akt pathway. Int Immunopharmacol. 9:886-893

Park SY, Kim YH, Kim EK, Ryu EY \& Lee SJ (2010) Heme oxygenase-1 signals are involved in preferential inhibition of pro-inflammatory cytokine release by surfactin in cells activated with Porphyromonas gingivalis lipopolysaccharide. Chem Biol Interact. 188:437-45

Pecci Y, Rivardo F, Martinotti MG \& Allegrone G (2010) LC/ESI-MS/MS characterisation of lipopeptide biosurfactants produced by the Bacillus licheniformis V9T14 strain J Mass Spectrom. 45:772-778

Perfumo A, Banat IM, Canganella F \& Marchant R (2006) Rhamnolipid production by a novel thermotolerant hydrocarbon-degrading Pseudomonas aeruginosa AP02-1. J Appl Microbiol. 75:132-138

Perfumo A, Smyth TJP, Marchant R \& Banat IM (2010a) Production and roles of biosurfactants and bioemulsifiers in accessing hydrophobic substrates, In: Handbook of Hydrocarbon and Lipid Microbiology, Timmis KN Ed., pp. 1501-1512, SpringerVerlag, Berlin Heidelberg, Germany

Perfumo A, Rancich I \& Banat IM (2010b). Possibilities and challenges for biosurfactants uses in petroleum industry, In: Biosurfactants, BIOSURFACTANTS Book Series: Advances in Experimental Medicine and Biology, Sen R Ed., Volume: 672, pp. 135145, Landes Bioscience, Austin, TX

Petrelli D, Zampaloni C, D'Ercole S, Prenna M, Ballarini P, Ripa S \& Vitali LA (2006) Analysis of different genetic traits and their association with biofilm formation in Staphylococcus epidermidis isolates from central venous catheter infections. Eur J Clin Microbiol Infect Dis. 25:773-781

Peypoux F, Bonmatin JM \& Wallach J (1999) Recent trends in the biochemistry of surfactin. Appl Microbiol Biotechnol. 51:553-563

Peypoux F, Guinand M, Michel G, Delcambe L, Das BC \& Lederer E (1978) Structure of iturin A, a peptidolipid antibiotic from Bacillus subtilis. Biochemistry. 17:3992-3996

Peypoux F, Pommier MT, Marion D, Ptak M, Das BC \& Michel G 1986. Revised structure of mycosubtilin, a peptidolipid antibiotic from Bacillus subtilis. J. Antibiot. (Tokyo) 39:636-641 
Peypoux F, Pommier MT, Das BC, Besson F, Delcambe L \& Michel G (1984) Structures of bacillomycin D and bacillomycin L peptidolipid antibiotics from Bacillus subtilis. J. Antibiot. (Tokyo) 77:1600-1604

Pierce D \& Heilman TJ (2001) Germicidal composition. US Patent 6262038, 17 July

Pissuwan D, Niidome T \& Cortie MB (2011) The forthcoming applications of gold nanoparticles in drug and gene delivery systems. J Control Release. 149:65-71

Pissuwan D, Valenzuela SM, Miller CM, Killingsworth MC \& Cortie MB (2009) Destruction and control of Toxoplasma gondii tachyzoites using gold nanosphere/antibody conjugates. Small. 5:1030-1034.

Ramisse F, Delden C, Gidenne S et al. (2000) Decreased virulence of a strain of Pseudomonas aeruginosa $\mathrm{O} 12$ overexpressing a chromosomal type $1 \beta$-lactamase could be due to reduced expression of cell-to-cell signalling dependent virulence factors. FEMS Immunol Med Microbiol. 28:241-245

Rasmussen TB \& Givskov M (2006) Quorum-sensing inhibitors as antipathogenic drugs. Int J Med Microbiol. 296:149-161

Raya A, Sodagari M, Pinzon NM, He X, Newby BZ \& Ju LK (2010) Effects of rhamnolipids and shear on initial attachment of Pseudomonas aeruginosa PAO1 in glass flow chambers. Environ Sci Pollut Res. 17:1529-1538

Raza ZA, Khalid ZM \& Banat IM (2009) Characterization of rhamnolipids produced by a Pseudomonas aeruginosa mutant strain grown on waste oils. J Environ Sci Health A Tox Hazard Subst Environ Eng. 44:1367-1373

Raza ZA, Khalid ZM, Khan MS, Banat IM, Rehman A, Naeem A \& Saddique MT (2010) Surface properties and sub-surface aggregate assimilation of Rhamnolipid surfactants in different aqueous system. Biotechnol Lett. 32:811-816

Reddy AS, Chen CY, Chen CC, Jean JS, Chen HR, Tseng MJ, Fan CW \& Wang JC. (2010) Biological synthesis of gold and silver nanoparticles mediated by the bacteria Bacillus subtilis. J Nanosci Nanotechnol. 10:6567-74

Reddy AS, Chen CY, Chen CC, Jean JS, Fan CW, Chen HR, Wang JC \& Nimje VR (2009) Synthesis of gold nanoparticles via an environmentally benign route using a biosurfactant. J Nanosci Nanotechnol. 9:6693-6699

Reid G, Bruce A \& Smeianov V (1998) The role of Lactobacilli in preventing urogenital and intestinal infections. Int Dairy J. 8:555-562

Reid G, Bruce AW, Busscher HJ \& Van der Mei HC (2000) Lactobacillus therapies. US Patent 605155218 April

Reid G, Bruce AW, Fraser N, Heinemann C, Owen J \& Henning B (2001) Oral probiotics can resolve urogenital infections. FEMS Immunol Med Microbiol. 30:49-52

Remichkova M, Galabova D, Roeva I, Karpenko E, Shulga A \& Galabov AS (2008) Antiherpesvirus activities of Pseudomonas sp. S-17 rhamnolipid and its complex with alginate. Z Naturforsch C. 63:75-81

Rivardo F, Martinotti MG, Turner RJ \& Ceri H (2010) The activity of silver against Escherichia coli biofilm is increased by a lipopeptide biosurfactant. Can. J. Microbiol. 56:272-278

Rivardo F, Martinotti MG, Turner RJ \& Ceri H (2011) Synergistic effect of lipopeptide biosurfactant with antibiotics against Escherichia coli CFT073 biofilm. Int J Antimicrob Agents. 37:324-331 
Rivardo F, Turner RJ, Allegrone G \& Ceri H, Martinotti MG (2009) Anti-adhesion activity of two biosurfactants produced by Bacillus spp. prevents biofilm formation of human bacterial pathogens. Appl Microbiol Biotechnol. 83:541-553

Rodrigues L, Banat IM, Teixeira J \& Oliveira R (2006a) Biosurfactants: potential applications in medicine. J Antimicrob Chemother. 57:609-618

Rodrigues L, van der Mei H, Banat IM, Teixeira J \& Oliveira R (2006b) Inhibition of microbial adhesion to silicone rubber treated with biosurfactant from Streptococcus thermophilus A. FEMS Immunol Med Microbiol. 46:107-112

Rodrigues L, van der Mei HC, Teixeira J \& Oliveira R (2004a) Biosurfactant from Lactococcus lactis 53 inhibits microbial adhesion on silicone rubber. Appl Microbiol Biotechnol. 66:306-311.

Rodrigues L, van der Mei HC, Teixeira J \& Oliveira R (2004b) Influence of biosurfactants from probiotic bacteria on formation of biofilms on voice prosthesis. Appl Environ Microbiol 70:4408-4410.

Rodrigues L, Banat IM, van der Mei HC, Teixeira JA, Oliveira R \& Oliveira R (2006c) Interference in adhesion of bacteria and yeasts isolated from explanted voice prostheses to silicone rubber by rhamnolipid biosurfactants. J Appl Microbiol. 100:470-480.

Rodrigues L, Banat IM, Teixeira J \& Oliveira R (2007) Strategies for the prevention of microbial biofilm formation on silicone rubber voice prostheses. J Biomed Mater Res B Appl Biomater. 81B:358-370.

Rodrigues LR, Teixeira JA, van der Mei HC \& Oliveira R (2006d) Physicochemical and functional characterization of a biosurfactant produced by Lactococcus lactis 53 . Colloids Surf B Biointerfaces. 49:79-86

Rodrigues LR \& Teixeira JA (2010) Biomedical and therapeutic applications of biosurfactants. Adv Exp Med Biol. 672:75-87

Ron EZ \& Rosenberg E (2001) Natural roles of biosurfactants. Environ Microbiol. 3:229-236

Rosenberg E \& Ron EZ (1997) Bioemulsans: microbial polymeric emulsifiers. Curr Opin Biotechnol. 8:313-316

Rosenberg E \& Ron EZ (1999) High- and low-molecular-mass microbial surfactants. Appl Microbiol Biotechnol 52:154-162

Rosenberg E, Zuckerberg A, Rubinovitz C \& Gutnick DL (1979) Emulsifier of Arthrobacter RAG-1:isolation and emulsifying properties. Appl Environ Microbiol. 37:402-408

Rosenberg M (2006) Microbial adhesion to hydrocarbons: twenty-five years of doing MATH. FEMS Microbiol Lett. 262:129-134

Rufino RD, Luna JM, Sarubbo LA, Rodrigues LR, Teixeira JA \& Campos-Takaki GM (2011) Antimicrobial and anti-adhesive potential of a biosurfactant Rufisan produced by Candida lipolytica UCP 0988. Colloids Surf B Biointerfaces. 84:1-5

Saini HS, Barragán-Huerta BE, Lebrón-Paler A, Pemberton JE, Vázquez RR, Burns AM, Marron MT, Seliga CJ, Gunatilaka AA \& Maier RM (2008) Efficient purification of the biosurfactant viscosin from Pseudomonas libanensis strain M9-3 and its physicochemical and biological properties. J Nat Prod. 71:1011-1015

Sánchez M, Aranda FJ, Teruel JA, Espuny MJ, Marqués A, Manresa Á \& Ortiz A (2010) Permeabilization of biological and artificial membranes by a bacterial dirhamnolipid produced by Pseudomonas aeruginosa. J Colloid Interface Sci. 341:240247 
Sánchez M, Aranda FJ, Teruel JA \& Ortiz A (2009) Interaction of a bacterial dirhamnolipid with phosphatidylcholine membranes: a biophysical study. Chem Phys Lipids. 161:51-55

Saravanakumari P \& Mani K (2010) Structural characterization of a novel xylolipid biosurfactant from Lactococcus lactis and analysis of antibacterial activity against multi-drug resistant pathogens. Bioresour Technol. 101:8851-8854

Satpute SK, Banat IM, Dhakephalkar PK, Banpurkar AG, Chopade BA (2010a) Biosurfactants, bioemulsifiers and exopolysaccharides from marine microorganisms. Biotechnol Adv. 28:436-450

Satpute SK, Banpurkar AG, Dhakephalkar PK, Banat IM \& Chopade BA (2010b) Methods for investigating biosurfactants and bioemulsifiers: a review. Crit Rev Biotechnol. 30:127-144

Selvam R, Maheswari P, Kavitha P, Ravichandran M, Sas B \& Ramchand CN (2009) Effect of Bacillus subtilis PB6, a natural probiotic on colon mucosal inflammation and plasma cytokines levels in inflammatory bowel disease. Indian J Biochem Biophys. 46:79-85

Seydlová G \& Svobodová J (2008) Review of surfactin chemical properties and the potential biomedical applications. Cent Eur J Med. 3:123-133

Shah V, Doncel GF, Seyoum T, Eaton KM, Zalenskaya I, Hagver R,Azim A \& Gross R (2005) Sophorolipids, microbial glycolipids with anti-human immunodeficiency virus and sperm-immobilizing activities. Antimicrob Agents Chemother. 49:4093-4100

Shaligram NS \& Singhal RS (2010) Surfactin - A review, on biosynthesis, fermentation, purification and applications. Food Technol Biotechnol. 48:119-134

Shao Z (2010) Trehalolipids, In: Biosurfactants: From Genes to Applications, Soberón-Chávez G Ed., pp. 121-143, Springer, Münster, Germany

Sharma VK., Yngard RA \& Lin Y (2009) Silver nanoparticles: Green synthesis and their antimicrobial activities. Adv Colloid Interfac. 145:83-96

Shete AM, Wadhava G, Banat IB \& Chopade BA (2006) Mapping of patents on bioemulsifiers and biosurfactants : A review. J Sci Ind Res (India). 65:91-115.

Singh A, van Hamme JD \& Ward OP (2007) Surfactants in microbiology and biotechnology: part 2. Application aspects. Biotechnol Adv. 25:99-121

Singh BR, Dwivedi S, Al-Khedhairy AA \& Musarrat J (2011) Synthesis of stable cadmium sulfide nanoparticles using surfactin produced by Bacillus amyloliquifaciens strain KSU-109. Colloids Surf B Biointerfaces. In press

Singh P \& Cameotra SS (2004) Potential applications of microbial surfactants in biomedical sciences. Trends Biotechnol. 22:142-146

Singh S, D’Britto V, Prabhune AA, Ramana CV, Dhawan A \& Prasad BLV (2010) A Cytotoxic and genotoxic assessment of glycolipid-reduced and -capped gold and silver nanoparticles. New J Chem. 34:294-301

Singh S, Patel P, Jaiswal S, Prabhune AA, Ramana CV \& Prasad BLV (2009) A direct method for the preparation of glycolipid-metal nanoparticle conjugates: sophorolipids as reducing and capping agents for the synthesis of water re-dispersible silver nanoparticles and their antibacterial activity. New J Chem. 33:646-652

Sivapathasekaran, C, Das P, Mukherjee S, Saravanakumar J, Mandal M \& Sen R (2010) Marine bacterium derived lipopeptides: characterization and cytotoxic activity against cancer cell lines. Int J Pept Res Ther. 16:215-222 
Smyth TJP, Perfumo A, Marchant R \& Banat IM (2010a) Isolation and analysis of low molecular weight microbial glycolipids, In: Handbook of Hydrocarbon and Lipid Microbiology, Timmis KN Ed., pp. 3705-3723, Springer, Berlin,

Smyth TJ, Perfumo A, Marchant R, Banat IM, Chen M, Thomas RK, Penfold J, Stevenson PS \& Parry NJ (2010b) Directed microbial biosynthesis of deuterated biosurfactants and potential future application to other bioactive molecules. Appl Microbiol Biotechnol. 87:1347-1354

Smyth TJP, Perfumo A, McClean S, Marchant R \& Banat IM (2010c) Isolation and analysis of lipopeptides and high molecular weight biosurfactants, In: Handbook of Hydrocarbon and Lipid Microbiology, Timmis KN Ed., pp. 3689-3704, Springer, Berlin, Germany

Soberón-Chávez G \& Maier RM (2010) Biosurfactants: a general overview, In: Biosurfactants: From Genes to Applications, Soberón-Chávez G Ed., pp. 1-11, Springer, Münster, Germany

Sotirova AV, Spasova DI, Galabova DN, Karpenko E \& Shulga A (2008) Rhamnolipidbiosurfactant permeabilizing effects on gram-positive and gram-negative bacterial strains. Curr Microbiol. 56:639-644

Stepanovic S, Cirkovic I, Ranin L \& Svabic-Vlahovic M (2004) Biofilm formation by Salmonella spp. and Listeria monocytogenes on plastic surface. Lett Appl Microbiol. 38:428-432

Stickler DJ (2008) Bacterial biofilms in patients with indwelling urinary catheters. Nat Clin Pract Urol. 5:598-608

Suzuki M, Kitagawa M, Yamamoto S, Sogabe A, Kitamoto D, Morita T, Fukuoka T \& Imura $\mathrm{T}$ (2010) Activator including biosurfactant as active ingredient, mannosyl erythritol lipid, and production method publication. Patent application number: 20100168405, 7 January

Tanaka Y, Tojo T, Uchida K, Uno J, Uchida Y \& Shida O (1997) Method of producing iturin A and antifungal agent for profound mycosis. Biotechnol Adv. 15:234-235

Tang JS, Zhao F, Gao H, Dai Y, Yao ZH, Hong K, Li J, Ye WC \& Yao XS (2010) Characterization and online detection of surfactin isomers based on HPLC-MSn analyses and their inhibitory effects on the overproduction of nitric oxide and the release of TNF- $\alpha$ and IL-6 in LPS-induced macrophages. Mar Drugs. 8:2605-2618.

Thavasi R, Jayalakshmi S, Balasubramanian T \& Banat IM (2008) Production and characterization of a glycolipid biosurfactant from Bacillus megaterium using economically cheaper sources. World J Microbiol Biotechnol. 24:917-925

Thavasi R, Jayalakshmi S \& Banat IM (2011) Effect of biosurfactant and fertilizer on biodegradation of crude oil by maring isolates of Bacillus megaterium and Corynebacterium kutscheri and Pseudomonas aeruginosa. Bioresouce Technol. 102:772778

Ueno Y, Hirashima N, Inoh Y, Furuno T \& Nakanishi M (2007a) Characterization of biosurfactant-containing liposomes and their efficiency for gene transfection. Biol Pharm Bull. 30:169-172

Ueno Y, Inoh Y, Furuno T, Hirashima N, Kitamoto D \& Nakanishi M (2007b) NBDconjugated biosurfactant (MEL-A) shows a new pathway for transfection. J Control Release. 123:247-253 
Valle J, Da Re S, Henry N, Fontaine T, Balestrino D, Latour-Lambert P \& Ghigo JM (2006) Broad-spectrum biofilm inhibition by a secreted bacterial polysaccharide. Proc Natl Acad Sci USA. 103:12558-12563

Van Bogaert INA \& Soetaert W (2010) Sophorolipids. In: Biosurfactants: From Genes to Applications, Soberón-Chávez G Ed., pp. 179-210, Springer, Münster, Germany

Van Bogaert INA, Saerens K, De Muynck C, Develter D, Wim S \& Vandamme EJ (2007) Microbial production and application of sophorolipids. Appl Microbiol Biotechnol. 76:23-34

Van der Mei HC, Free RH, Elving GJ, van Weissenbruch R, Albers FWJ \& Busscher HJ (2000) Effect of probiotic bacteria on prevalence of yeasts in oropharyngeal biofilms on silicone rubber voice prostheses in vitro. J Med Microbiol. 49:713-718.

Van Hamme JD, Singh A \& Ward OP (2006) Physiological aspects Part 1 in a series of papers devoted to surfactants in microbiology and biotechnology. Biotechnol Adv. 24:604620

Van Hoogmoed CG, Dijkstra RJB, van der Mei HC \& Busscher HJ (2006) Influence of biosurfactant on interactive forces between mutans streptococci and enamel measured by atomic force microscopy. J Dent Res. 85:54-58

Van Hoogmoed CG, van Der Kuijl-Booij M, van der Mei HC \& Busscher HJ (2000) Inhibition of Streptococcus mutans NS adhesion to glass with and without a salivary conditioning film by biosurfactant-releasing Streptococcus mitis strains. Appl Environ Microbiol. 66:659-663.

Van Hoogmoed CG, Van der Mei HC \& Busscher HJ (2004) The influence of biosurfactants released by $S$. mitis BMS on the adhesion of pioneer strains and cariogenic bacteria. Biofouling, 20:261-267

Vanittanakom, N, Loeffler W, Koch U \& Jung G (1986) Fengycin-a novel antifungal lipopeptide antibiotic produced by Bacillus subtilis F-29-3. J. Antibiot. (Tokyo). 39:888-901

Velraeds MMC, van de Belt-Gritter B, Busscher HJ, Reid G \& van der Mei HC (2000) Inhibition of uropathogenic biofilm growth on silicone rubber in human urine by lactobacilli - a teleologic approach. World J Urol. 18:422-426.

Velraeds MMC, Van der Mei HC, Reid G \& Busscher HJ (1996) Inhibition of initial adhesion of uropathogenic Enterococcus faecalis by biosurfactants from Lactobacillus isolates. Appl Environ Microbiol. 62:1958-1963.

Velraeds MMC, Van der Mei HC, Reid G \& Busscher HJ (1997) Inhibition of initial adhesion of uropathogenic Enterococcus faecalis to solid substrata by an adsorbed biosurfactant layer from Lactobacillus acidophilus. Urology. 49:790-794.

Vollenbroich D, Ozel M, Vater J, Kamp RM \& Pauli G (1997a) Mechanism of inactivation of enveloped viruses by the biosurfactant surfactin from Bacillus subtilis. Biologicals. 25:289-297

Vollenbroich D, Pauli G, Ozel M \& Vater J (1997b) Antimycoplasma properties and application in cell culture of surfactin, a lipopeptide antibiotic from Bacillus subtilis. Appl. Environ. Microbiol. 63:44-49

von Eiff C, Kohnen W, Becker K \& Jansen B (2005) Modern strategies in the prevention of implant-associated infections. Int J Artif Organs. 28:1146-1156 
Walencka E, Różalska S, Sadowska B \& Różalska B (2008) The influence of Lactobacillus acidophilus derived surfactants on staphylococcal adhesion and biofilm formation. Folia Microbiol. 53:61-66

Worakitkanchanakul W, Imura T, Fukuoka T, Morita T, Sakai H, Abe M, Rujiravanit R, Chavadej S, Minamikawa H \& Kitamoto D (2008) Aqueous-phase behavior and vesicle formation of natural glycolipid biosurfactant, mannosylerythritol lipid-B. Colloids Surf B Biointerfaces. 65:106-112

Xie Y, Li Y \& Ye R (2005) Effect of alcohols on the phase behavior of microemulsions formed by a biosurfactant-rhamnolipid. J Dispers Sci Technol. 26:455-461

Xie Y, Ye R \& Liu H (2006) Synthesis of silver nanoparticles in reverse micelles stabilized by natural biosurfactant. Colloid Surf A-Physicochem Eng Asp. 279:175-178

Xie YW, Ye RQ \& Liu HL (2007) Microstructure studies on biosurfactant-rhamnolipid/nbutanol/water/n-heptane microemulsion system. Colloid Surf A-Physicochem Eng Asp. 292:189-195

Yakimov MM, Timmis KN, Wray V \& Fredrickson HL (1995) Characterization of a new lipopeptide surfactant produced by thermotolerant and halotolerant subsurface Bacillus licheniformis BAS 50. Appl Environ Microbiol. 61:1706-1713

Yoo DS, Lee BS \& Kim EK (2005) Characteristics of microbial biosurfactant as an antifungal agent against plant pathogenic fungus J Microbiol Biotechnol. 15:1164-1169

Zaragoza A, Aranda FJ, Espuny MJ, Teruel JA, Marqués A, Manresa Á \& Ortiz A (2009) Mechanism of membrane permeabilization by a bacterial trehalose lipid biosurfactant produced by Rhodococcus sp. Langmuir. 25:7892-7898

Zaragoza A, Aranda FJ, Espuny MJ, Teruel JA, Marqués A, Manresa Á \& Ortiz A (2010) Hemolytic activity of a bacterial trehalose lipid biosurfactant produced by Rhodococcus sp.: evidence for a colloid-osmotic mechanism. Langmuir. 26(11):85678572

Zeraik AE \& Nitschke M (2010) Biosurfactants as agents to reduce adhesion of pathogenic bacteria to polystyrene surfaces: effect of temperature and hydrophobicity. Curr Microbiol. 61:554-559 


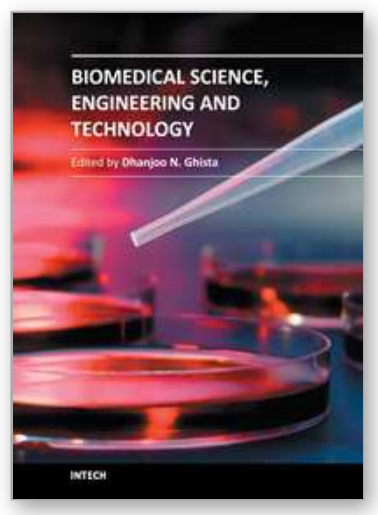

\author{
Biomedical Science, Engineering and Technology \\ Edited by Prof. Dhanjoo N. Ghista
}

ISBN 978-953-307-471-9

Hard cover, 902 pages

Publisher InTech

Published online 20, January, 2012

Published in print edition January, 2012

This innovative book integrates the disciplines of biomedical science, biomedical engineering, biotechnology, physiological engineering, and hospital management technology. Herein, Biomedical science covers topics on disease pathways, models and treatment mechanisms, and the roles of red palm oil and phytomedicinal plants in reducing HIV and diabetes complications by enhancing antioxidant activity. Biomedical engineering coves topics of biomaterials (biodegradable polymers and magnetic nanomaterials), coronary stents, contact lenses, modelling of flows through tubes of varying cross-section, heart rate variability analysis of diabetic neuropathy, and EEG analysis in brain function assessment. Biotechnology covers the topics of hydrophobic interaction chromatography, protein scaffolds engineering, liposomes for construction of vaccines, induced pluripotent stem cells to fix genetic diseases by regenerative approaches, polymeric drug conjugates for improving the efficacy of anticancer drugs, and genetic modification of animals for agricultural use. Physiological engineering deals with mathematical modelling of physiological (cardiac, lung ventilation, glucose regulation) systems and formulation of indices for medical assessment (such as cardiac contractility, lung disease status, and diabetes risk). Finally, Hospital management science and technology involves the application of both biomedical engineering and industrial engineering for cost-effective operation of a hospital.

\title{
How to reference
}

In order to correctly reference this scholarly work, feel free to copy and paste the following:

Letizia Fracchia, Massimo Cavallo, Maria Giovanna Martinotti and Ibrahim M. Banat (2012). Biosurfactants and Bioemulsifiers Biomedical and Related Applications - Present Status and Future Potentials, Biomedical Science, Engineering and Technology, Prof. Dhanjoo N. Ghista (Ed.), ISBN: 978-953-307-471-9, InTech, Available from: http://www.intechopen.com/books/biomedical-science-engineering-andtechnology/biosurfactants-and-bioemulsifiers-biomedical-and-related-applications-present-status-and-futurepote

\section{INTECH}

open science | open minds

\section{InTech Europe}

University Campus STeP Ri

Slavka Krautzeka 83/A

51000 Rijeka, Croatia

Phone: +385 (51) 770447

\section{InTech China}

Unit 405, Office Block, Hotel Equatorial Shanghai

No.65, Yan An Road (West), Shanghai, 200040, China

中国上海市延安西路65号上海国际贵都大饭店办公楼 405 单元

Phone: +86-21-62489820 
Fax: +385 (51) 686166

Fax: +86-21-62489821

www.intechopen.com 
(C) 2012 The Author(s). Licensee IntechOpen. This is an open access article distributed under the terms of the Creative Commons Attribution 3.0 License, which permits unrestricted use, distribution, and reproduction in any medium, provided the original work is properly cited. 